\title{
Mechanical characteristics of laminated sand-shale sequences identified from sonic velocity and density correlations
}

\author{
Mao Bai $\mathbb{1}$
}

Received: 10 June 2016/ Accepted: 3 August 2016/Published online: 13 August 2016

(C) Springer International Publishing Switzerland 2016

\begin{abstract}
In the past, numerous relations between sonic velocity (i.e. an inverse of sonic travel time DT) and rock density were developed that were suitable for certain fields or certain rocks only. In this paper, the correlations between sonic and density log measurements were investigated again using the data information from multiple fields of Gulf of Mexico (GOM) and North Sea (NS). For sandstone-shale sequences, the dominant linear relationships between sonic travel time (DT) and formation density (RHOB) were observed, and compared with the popular Gardner's method (Gardner et al. in Geographics 39(6):770-780, 1974) along with other known methods. The implications of data clusters distinguished by formation lithologies and rock mechanical strengths were revealed from cross-plot analysis. The probabilities and uncertainties of the developed correlations were determined using the actual histograms from the collected data of GOM and NS fields coupled with Monte Carlo simulations.
\end{abstract}

Keywords Sonic velocity and density correlation . Mechanical properties $\cdot$ Sandstone-shale formation

M. Bai ( $₫)$

Geomechanics Consultant, Houston, TX, USA

e-mail: Mao-bai@excite.com

\section{Sonic velocity and density correlations}

It is recognized that the relationships between the rock sonic velocity and rock density depend on numerous factors such as rock strength and integrity, effective stress, mineral composition, granular structure, cementation, porosity, lithology, fluid content, saturation, micro-cracks, fluid pressure, depth of burial, geological age, and many other environmental conditions and factors (Horsfall et al. 2013).

Recognizing the significant variability between the sonic velocity and rock density, Gardner et al. (1974) derived an empirical relation between $\mathrm{P}$-wave velocity and density of various saturated sedimentary rocks from a series of controlled field and laboratory measurements as:

$\rho=0.23 \times V_{p}^{0.25}$

where $\rho$ is the density $\left(\mathrm{g} / \mathrm{cm}^{3}\right.$ or $\left.\mathrm{g} / \mathrm{cc}\right), V_{p}$ is the P-wave velocity (ft/s), 0.23 is the empirical magnitude constant, and 0.25 is the empirical shape constant.

Gardner's method has been widely used in oil/gas industry for sedimentary formations (e.g. offshore wells in Gulf of Mexico) with the primary purpose of deriving the rock density from P-wave velocity. With the increasing needs to interpret the formation mechanical properties from sonic velocity, Gardner's method has been also used to derive the P-wave velocity from density data, i.e. 
$V_{p}=357.346 \times \rho^{4}$

where $\rho$ is the density $\left(\mathrm{g} / \mathrm{cm}^{3}\right)$ and $V_{p}$ is the P-wave velocity ( $\mathrm{ft} / \mathrm{s})$.

Besides the Gardner's method, many other correlations between velocity and density exist. Potter and Stewart (1998) proposed an empirical relationship between S-wave velocity and density similar to Gardner's method:

$\rho=0.37 \times V_{s}^{0.22}$

where $V_{s}$ is the $\mathrm{S}$-wave velocity $(\mathrm{ft} / \mathrm{s})$ and $\rho$ is the density $\left(\mathrm{g} / \mathrm{cm}^{3}\right)$.

Birch (1961) gave an empirical linear relationship between P-wave velocity and density. Since the inverse of P-wave velocity is the transit travel time (i.e. $D_{T}$ ), the relationship between the density and sonic travel time becomes nonlinear as follows: $\rho=0.3623 \times\left(\frac{304.8}{D_{T}}+0.98\right)$

where $D_{T}$ is the transit travel time $(\mu \mathrm{s} / \mathrm{ft})$ and $\rho$ is the density $\left(\mathrm{g} / \mathrm{cm}^{3}\right)$.

The relationship between the transit travel time $\left(D_{T}\right)$ and the density $(\rho)$ similar to the one by Birth was given by Kozlovskaya et al. (2004) as:

$\rho=0.25 \times\left(\frac{304.8}{D_{T}}-5.5\right)+2.4$

where $D_{T}$ is the transit travel time $(\mu \mathrm{s} / \mathrm{ft})$ and $\rho$ is the density $\left(\mathrm{g} / \mathrm{cm}^{3}\right)$.

Lindseth (1979) offered a linear relationship between transit travel time $\left(D_{T}\right)$ and density $(\rho)$ as:

$\rho=3.247 \times\left(1-0.00346 \times D_{T}\right)$

where $D_{T}$ is the transit travel time $(\mu \mathrm{s} / \mathrm{ft})$ and $\rho$ is the density $\left(\mathrm{g} / \mathrm{cm}^{3}\right)$.

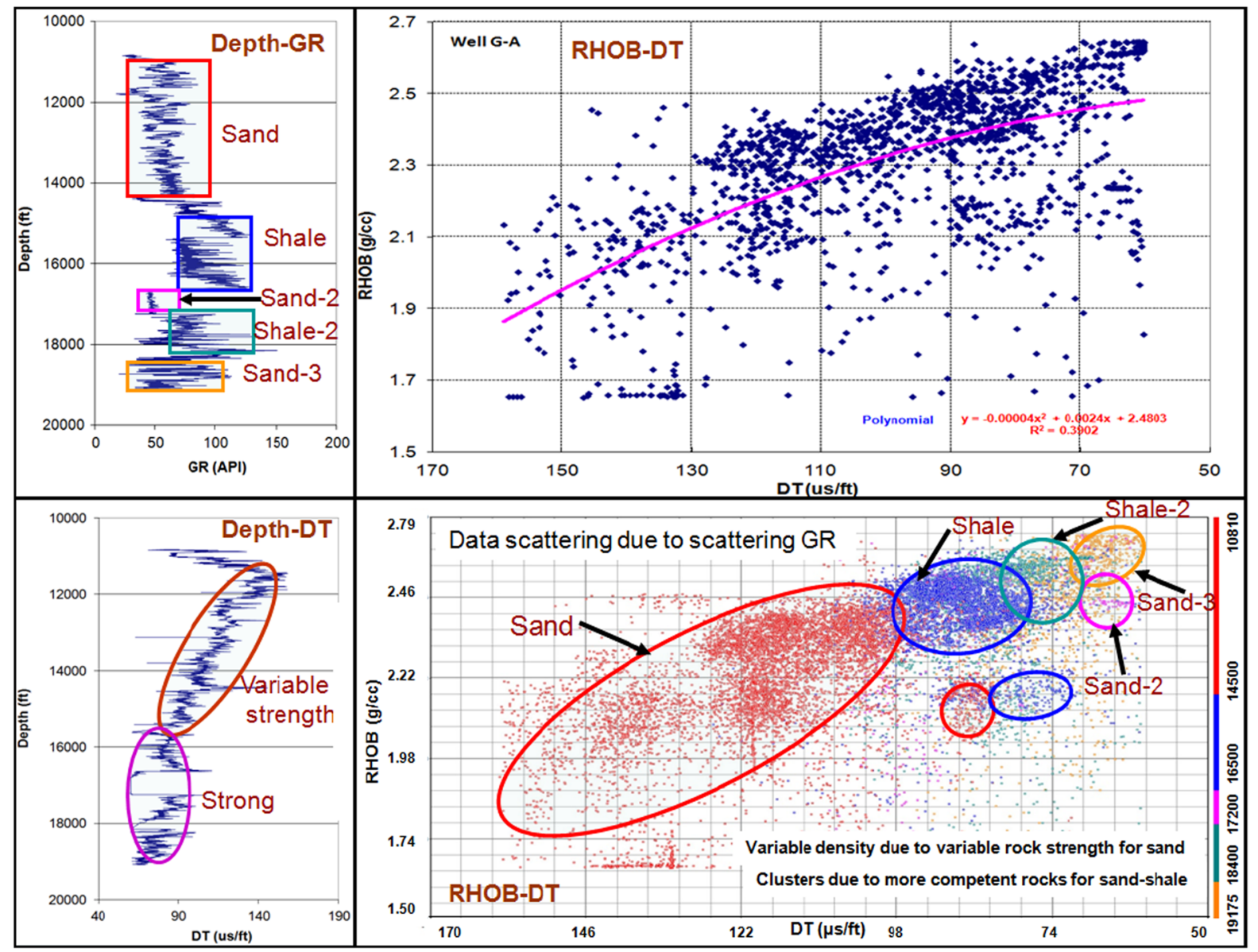

Fig. 1 Cross-plot of travel time (DT) and density (RHOB) for well G-A 


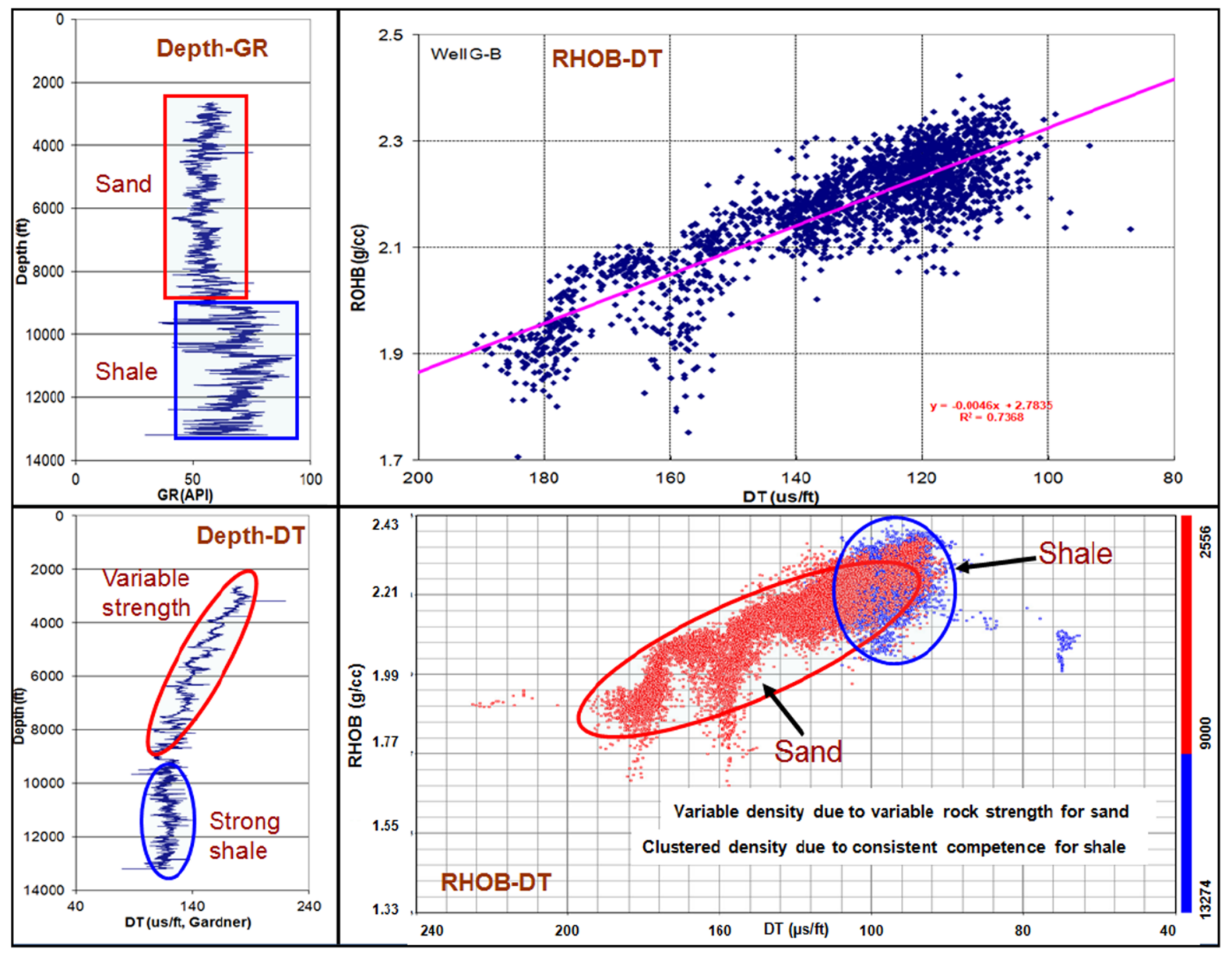

Fig. 2 Cross-plot of travel time (DT) and density (RHOB) for well G-B

In this paper, wire-line log data were collected from the fields of Gulf of Mexico (GOM) and North Sea (NS). For the data from each individual well, the relationships between sonic travel time (i.e. $D_{T}$ or DT in the figures) and density (i.e. $\rho$ or RHOB in the figures) were discussed with reference to rock lithology (i.e. Gamma Ray or GR in the figures) and rock strength (i.e. correlated by sonic log, e.g. from Lal 1999; Horsrud 2001). These relationships were quantified with relevant linear and nonlinear equations. The histograms of measured sonic and density data for each well were determined. The accumulative probability profiles were generated.

\section{Mechanical characteristics of laminated sand- shale sequences}

The purpose of this analysis is to determine whether the relationship between sonic travel time (DT) and density (RHOB) is affected by rock lithology (e.g. shale or sand) and by status of rock strength (e.g. weak or strong). In general, Gamma Ray (GR) should not be considered as a sole lithology indicator. For simplicity, however, GR is used to distinguish the shales from sandstones (sand for short). It should be noted that all selected "shales" have a relatively greater GR reading than "sands". Frequently, dirty sands and impure 


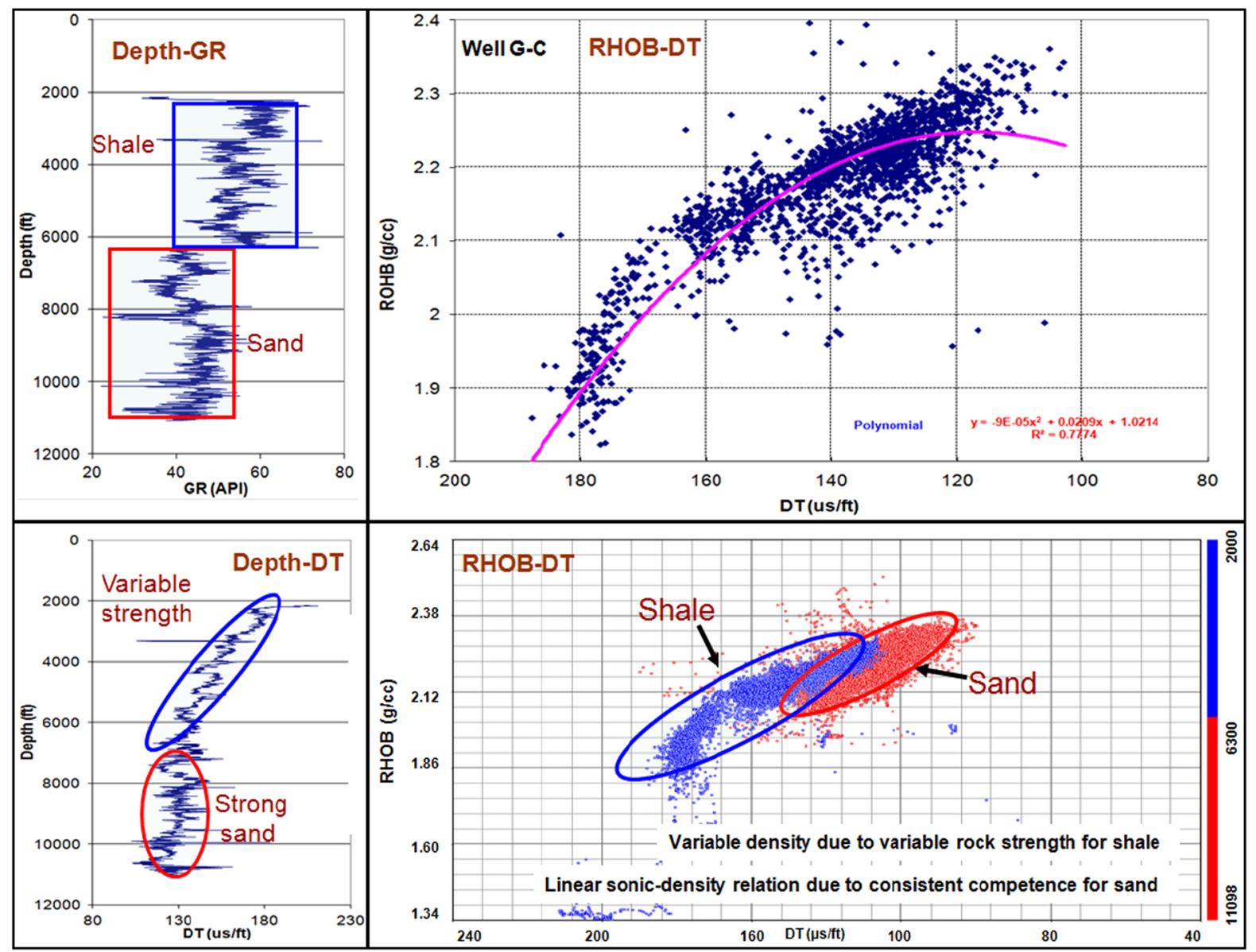

Fig. 3 Cross-plot of travel time (DT) and density (RHOB) for well G-C

shales are difficult to discern from GR reading. By the same token, "weak" rock is indicated by the relatively larger sonic transit travel time or smaller sonic velocity; and vice versa for "strong" rock. "Variable" strength may extend from "weak" to "strong". In consequence, many of subsequent judgments can be in a relative fashion and can be even subjective.

\subsection{Gulf of Mexico (GOM)}

Figure 1 depicts the cross plot of sonic-density logs. Based on the GR, three sand layers and two shale layers may be identified. From the DT, rock appears to be weaker at shallower formation and stronger at deeper section. The primary sand layer (red line) is also a weaker layer. Shales and deeper sands are strong and also clustered, which is in contrast to the smearing data for weaker and lighter rocks. The correlation between DT and RHOB is expressed as a polynomial of second order.

GR in Fig. 2 indicates that the formation composes of two layer system (i.e. sand and shale). DT reveals that sand gets stronger as the depth increases, and shale is strong. Good linear relationship between DT and RHOB is obtained. 


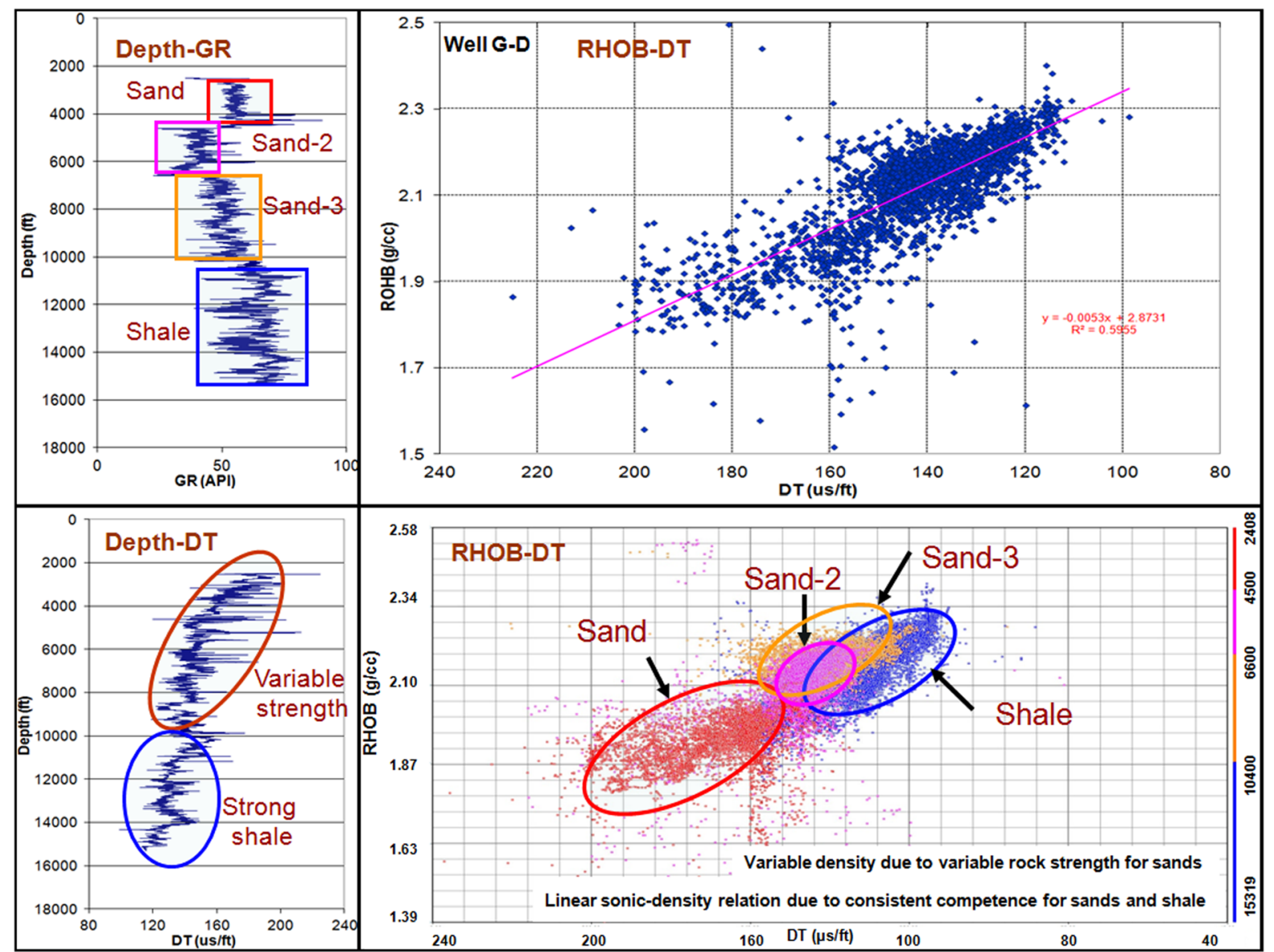

Fig. 4 Cross-plot of travel time (DT) and density (RHOB) for well G-D

In contrast to the case in Fig. 2, the scenario in Fig. 3 indicates the shallow variably weak shale and deep strong sand. The correlation between DT and RHOB is expressed as a polynomial of second order. Curved tailing in shale reflects the shallower, weaker and lighter part of the formation. Again, the linear relation between DT and RHOB lies in the stiffer strata (primary sand and partially shale).

The relation between DT and RHOB in Fig. 4 is apparently linear. The disappearance of the curved tail (see case in Fig. 3) is attributed to the relative competence of the rock at shallower depth (i.e. sands). In general, shallow sands are weaker and deep shale is stronger in this case.
The relationship between DT and RHOB in Fig. 5 is linear. Even though the GR shows the distinguished sand-shale sequence, the cross plot of DT-RHOB relation shows the significant data smearing and prevalent mixing of sand and shale clusters, an indication of persistently uniform rock strength as reflected in DT.

\subsection{North Sea (NS)}

The GR in Fig. 6 shows more diversified lithologies, while DT shows more variability on rock strength. The data depict two primary clusters-one for shallow weaker sand/shale with curved tail and one for deep 


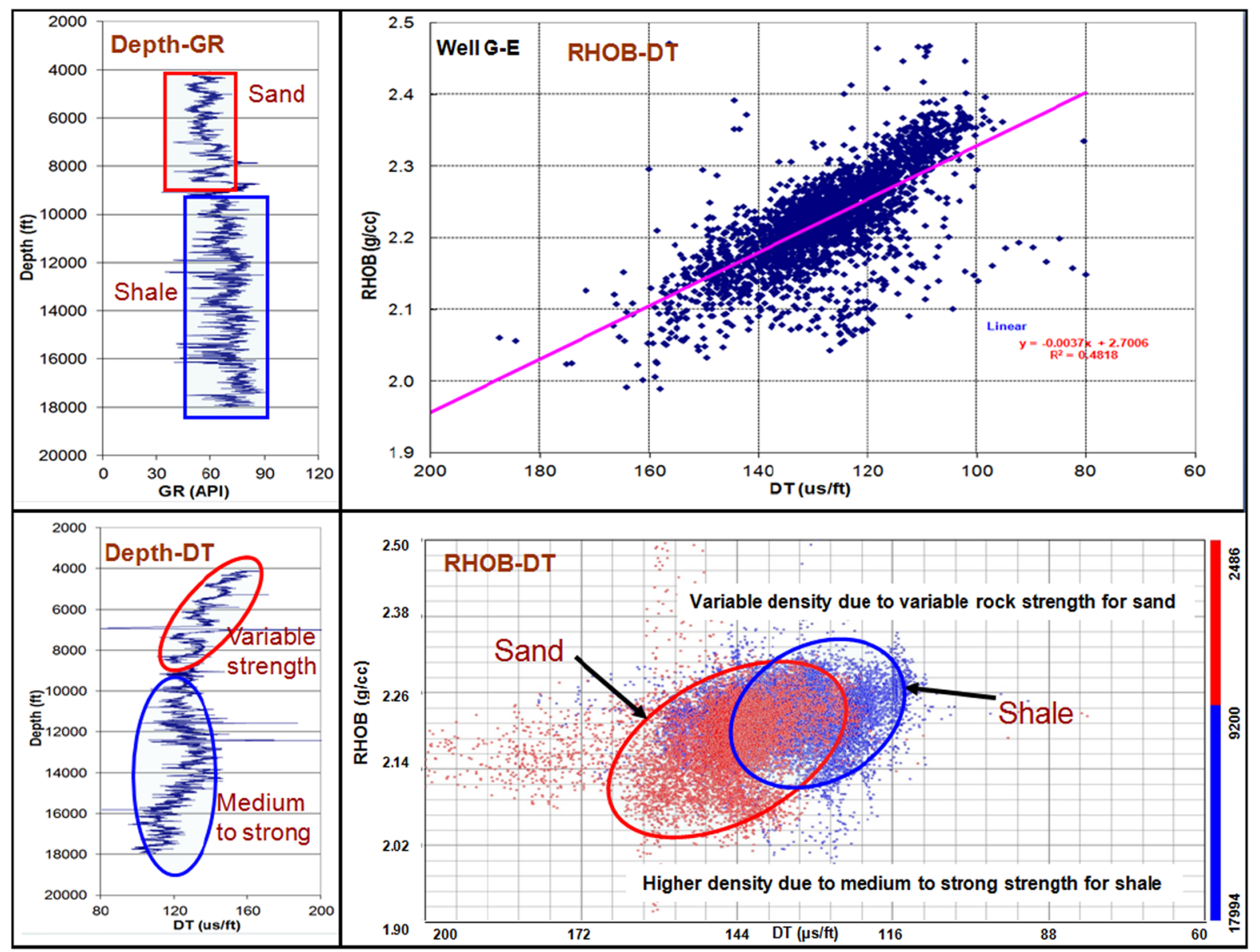

Fig. 5 Cross-plot of travel time (DT) and density (RHOB) for well G-E

stiffer sand/shale in circular cluster. The relationship between DT and RHIOB is highly nonlinear (i.e. a polynomial of third order).

Figure 7 shows an eventful case. Both strengths of sand and shale vary. An interesting observation is in the cross plot where three clusters are apparent. The medium to strong shale above the linear relation line of DT and RHOB consists of the first cluster, while strong and weak sands below the linear relation line consist of the second and third clusters. This scenario shows the similar response as reported by Gardner et al. (1974) and also by Sheriff and Geldart (1995), as shown in Fig. 8. It should be noted that the cross plot of DT in Fig. 7 and P-wave velocity in Fig. 8 are in the inverse relation, while the lateral unit of DT in Fig. 7 is in the reversed order. In any case, it appears that the linear line for DT and RHOB acts like a divider between sands and shales.

Figure 9 represents a scenario where shallow weak shale forms the tail cluster and deep strong sand constitutes the portion of linear cluster with substantial data scattering that is an indication of laminated sandshale sequence (see Depth-GR).

Figure 10 shows the linear relation between DT and RHOB. The shallow weak sand cluster does not show the curved tailing. The substantial data scattering from shale-2 is the result of significant variation on rock 


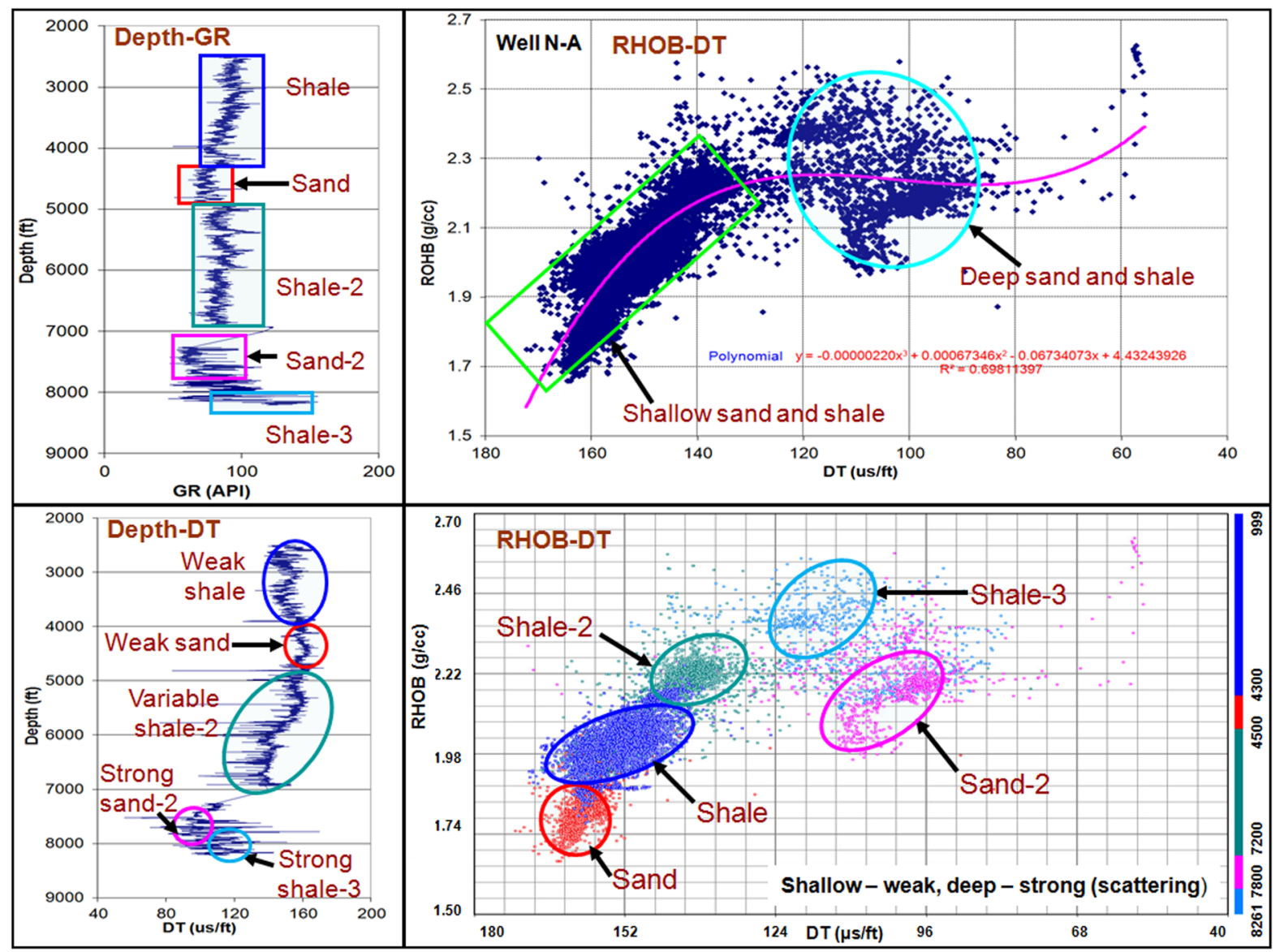

Fig. 6 Cross-plot of travel time (DT) and density (RHOB) for well N-A

lithology (see deeper hydrocarbon zone in Depth-GR chart).

Figure 11 indicates that sands are weak or intermediate. The DT-RHOB relationship of sands is linear. The deep section of shale is strong. However, the shale is very sandy (see Depth-GR). The shale data scattering at larger density range is the result of mixed sand-shale sequence. The relation between DT and RHOB is a polynomial of second order.

Figure 12 shows sand-shale layers with more variable strength (i.e. rock strength increases as the depth increases). Shallow shales are weak, while deep sands are strong. The DT-RHOB relation is linear.

Figure 13 shows the case where shallow shale is weak, and medium and deep sands are intermediate and strong. The DT-RHOB relation is linear.
Figure 14 displays shallow weak sand and associated vertical clusters. Shale is intermediate in strength. The deep sand is strong. The linear DT-RHOB relation is selected after neglecting the impact of shallow sand.

In Fig. 15, two contrasting clusters show that shales are weak to intermediate, while sands are medium to strong. The DT-RHOB relation is a polynomial of third order.

Figure 16 depicts the shallow weak shale with tail and deep strong sand. The relation between DT and RHOB is a polynomial of third order.

In Fig. 17, shallow shale is weak while deep shale is strong. The sand is intermediate and strong. The relation between DT and RHOB is apparently linear. 


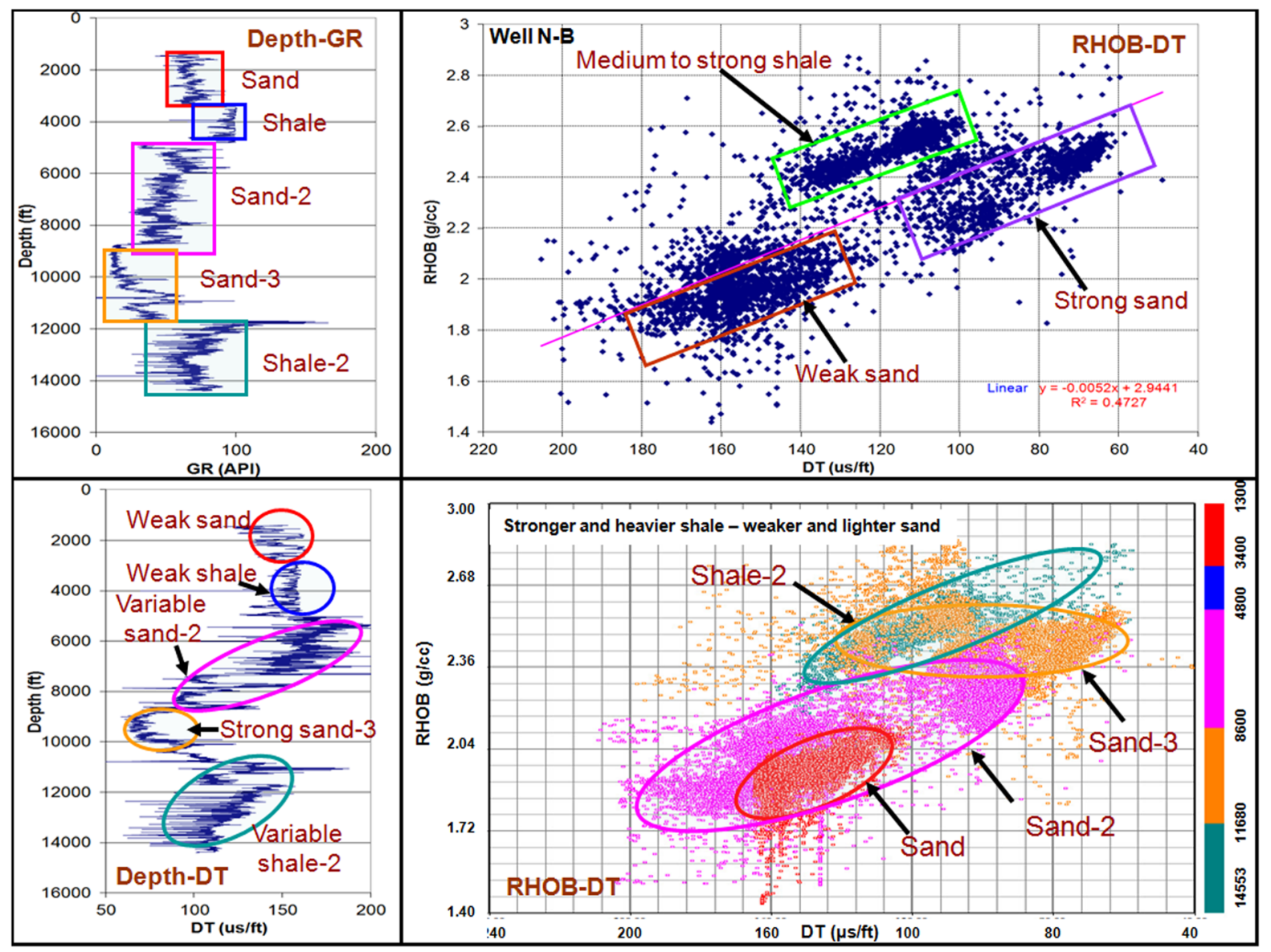

Fig. 7 Cross-plot of travel time (DT) and density (RHOB) for well N-B

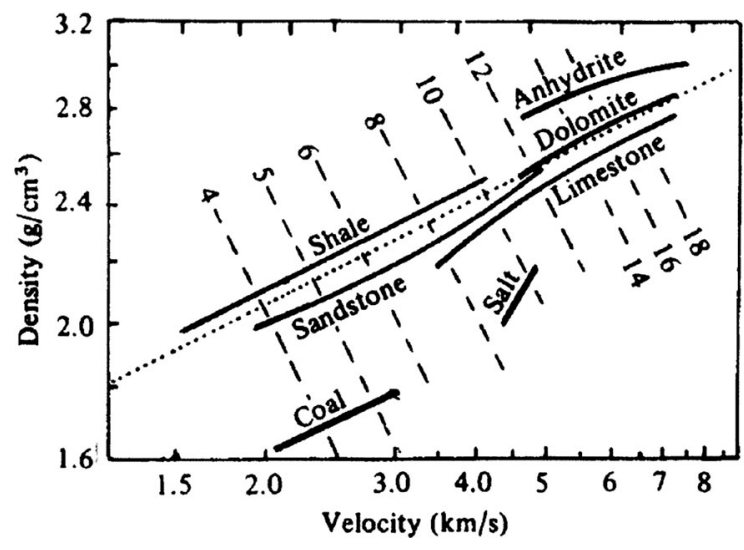

Fig. 8 Density versus P-wave velocity using Gardner's empirical relation (Sheriff and Geldart 1995)
Comparison of cross-plots between those using R-program (R Core Team 2012) and those of present study is given in Fig. 18 for wells $\mathrm{N}-\mathrm{G}$ and N-K, respectively. The differences in the colored clusters can be attributed to the subjective lithological selections (i.e. either shale or sand). However, general plot trends and lithological selections are similar.

\section{Linear relationships between sonic travel time and density}

In this section, the correlated sonic-density logs are graphically summarized. Analyzed DT-RHOB correlations seem to show dominant linear fashion. 


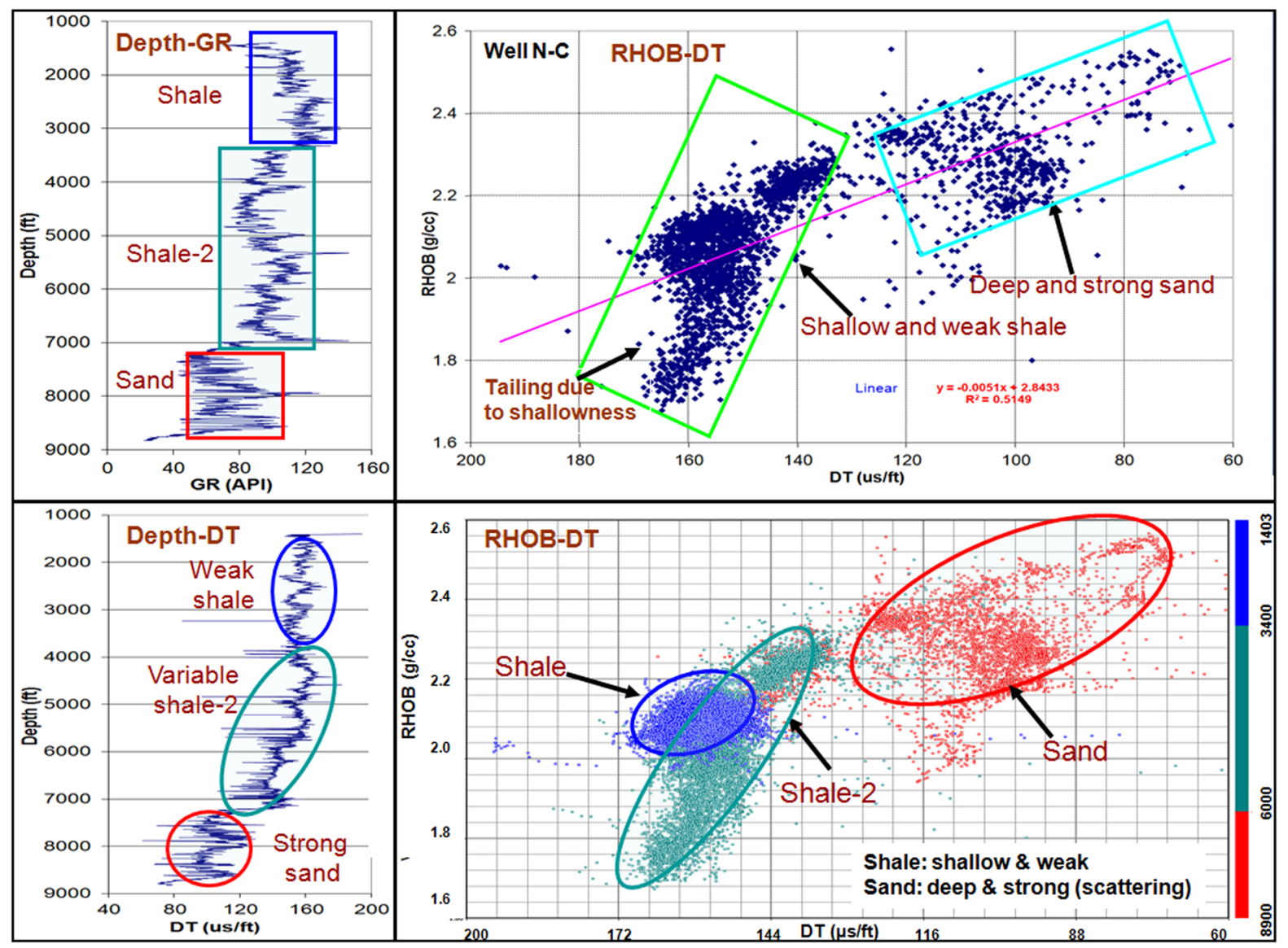

Fig. 9 Cross-plot of travel time (DT) and density (RHOB) for well N-C

All the relationships between DT and RHOB for Gulf of Mexico (GOM) are collected from the crossplot analysis and compared with the relations by Gardner et al. Gardner (1974), Birch (1961), Lindseth (1979) and Kozlovskaya et al. (2004) shown in the introduction section, as seen in Fig. 19. It is noted that most correlations from GOM are linear. The data from two wells in GOM that show nonlinear DT-RHOB correlations deviate from the other wells in the lower density region. Gardner's curve follows closely with the linear correlations of DT-RHOB from most of GOM wells. Non-Gardner's methods follow the general trend of nonlinear correlations.

Taking the nonlinear correlations out, the linear DT-RHOB correlations for GOM are compared with
Gardner's method in Fig. 20. It can be deduced that the result from Gardner's method was close to the data from GOM.

The linear relationship between sonic travel time (DT) and density (RHOB) takes the following form:

$\rho=A \times D T+B$

where the factor " $\mathrm{A}$ " has the negative value and the factor " $\mathrm{B}$ " has the positive value. For Gulf of Mexico (GOM), the range of " $A$ " is -0.0037 to -0.0059 , and the range of " $\mathrm{B}$ " is 2.6942-2.9593. " $\mathrm{A}$ " represents the slope of the linear line, while " $\mathrm{B}$ " is the intersection of the linear line at zero travel time. It may be noted that the lateral unit of DT in Fig. 20 is displayed in a reversed order. This display is aimed at showing 


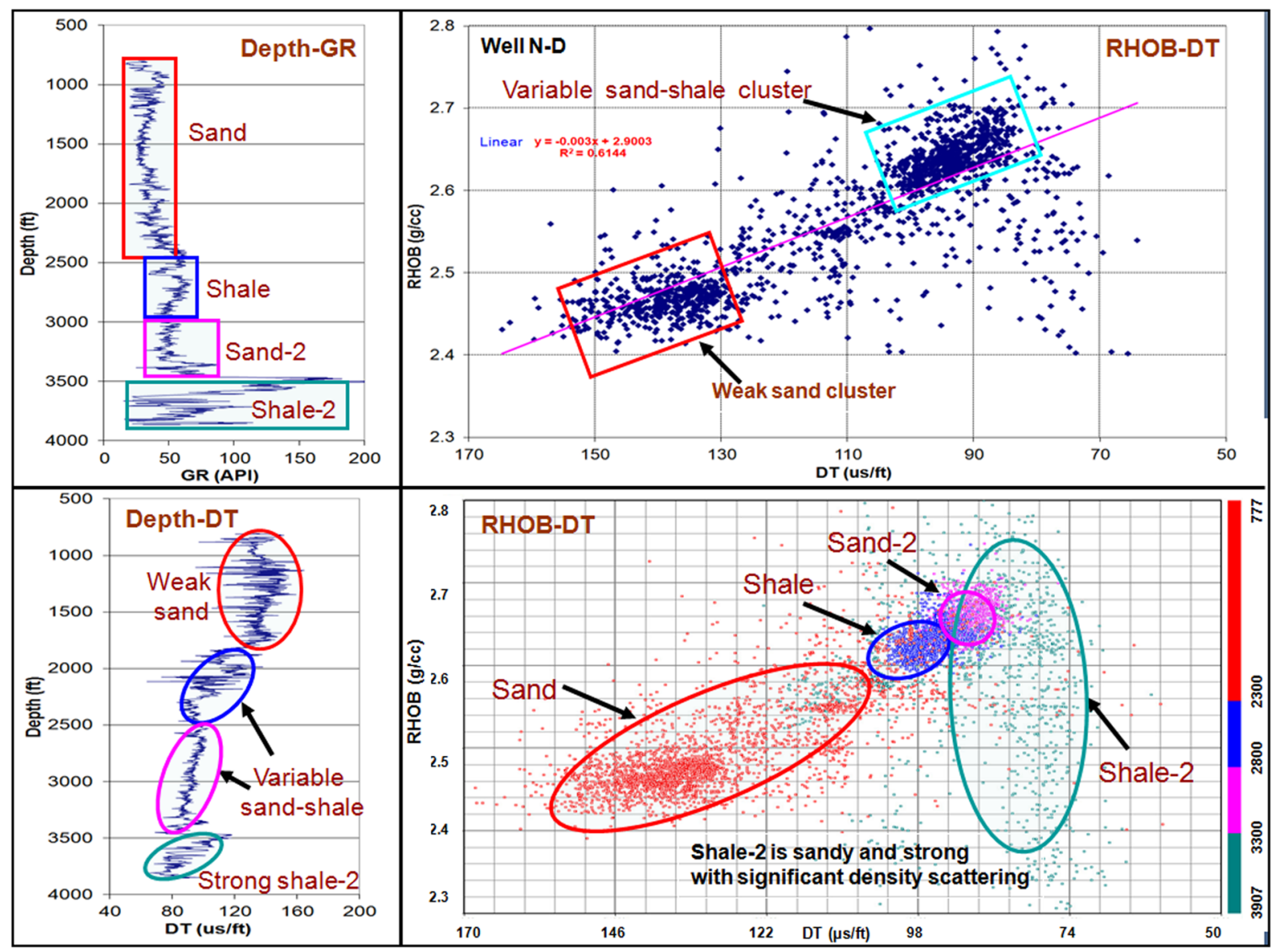

Fig. 10 Cross-plot of travel time (DT) and density (RHOB) for well N-D

weaker rock (i.e. larger travel time) at lower density range, and stronger rock (i.e. smaller travel time) at higher density range. From Fig. 20, it appears that Gardner's relation starts to deviate from the linear relation of GOM at the area where density is high and rock is strong.

All the correlations between DT and RHOB for North Sea (NS) are collected from the cross-plot analysis and are compared with the relations by Gardner et al. (1974), Birch (1961), Lindseth (1979) and Kozlovskaya et al. (2004) as shown in Fig. 21. Comparing the cases in Fig. 21 for North Sea to the cases in Fig. 19 for Gulf of Mexico, it is seen that densities vary more significantly for the latter cases. The common features, however, indicate that the linear relationships between DT and RHOB prevail.
Maintaining only the linear relationships for North Sea, the correlations are compared only with Gardner's relation in Fig. 22. Equation (7) is applied to derive the relations in Fig. 22 where the range of coefficient " $\mathrm{A}$ " is -0.003 to -0.0081 , and the range of coefficient " $\mathrm{B}$ " is 2.8433-3.22. The comparison of coefficients in the linear relationship of Eq. (7) between the cases for GOM and the cases for NS is shown in Table 1.

The comparison of collective linear correlations between DT and RHOB in the form of trend lines for GOM and for NS is given in Fig. 23. The trend lines for GOM and for NS are very close, even though the data from NS show much wider range than the data from GOM. The coefficients " $A$ " and " $B$ " of the trend lines for GOM and for NS are compared in Table 2. It 


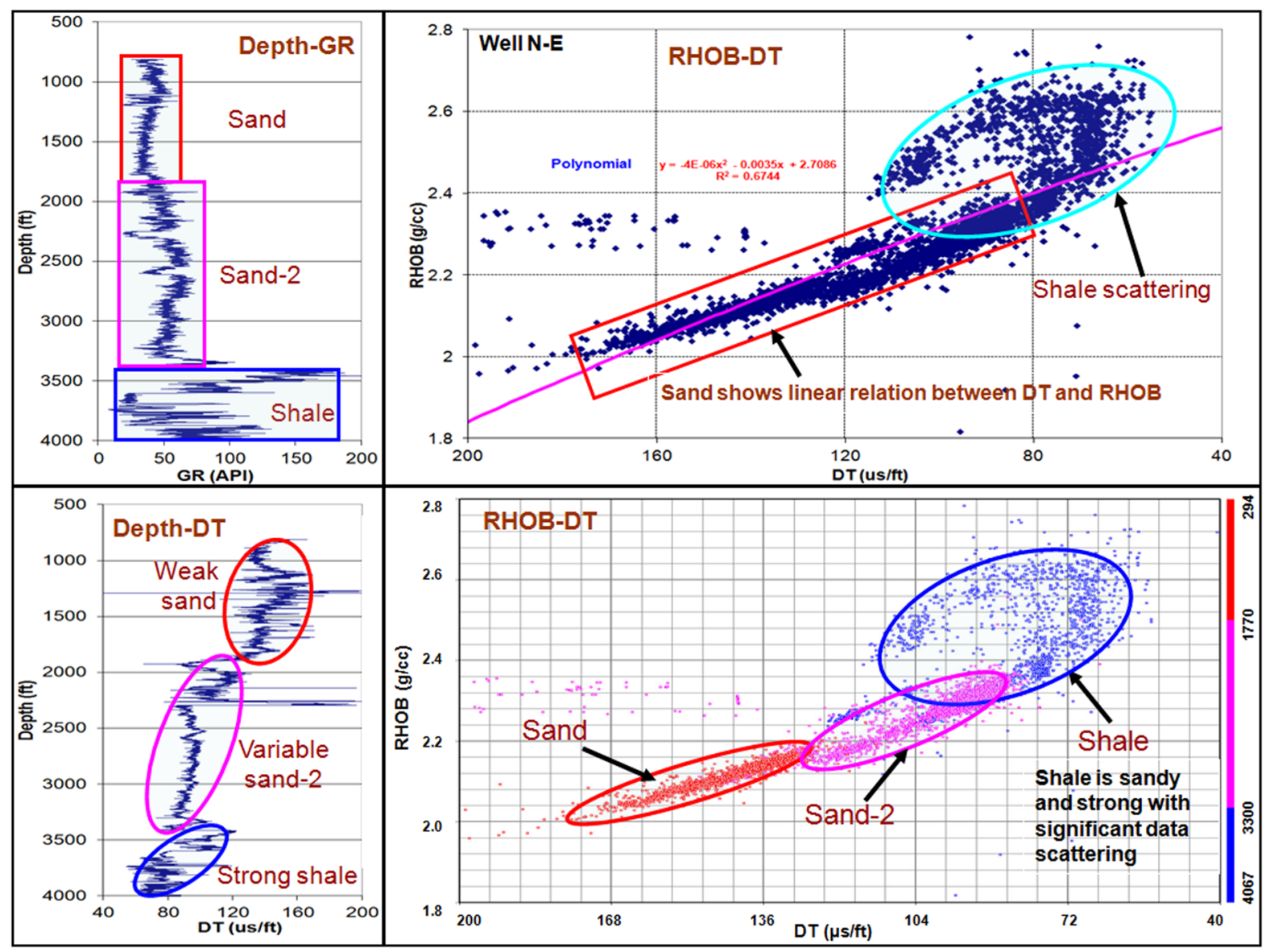

Fig. 11 Cross-plot of travel time (DT) and density (RHOB) for well N-E

is seen that coefficients are close between GOM and NS.

Comparisons of correlations between sonic travel time (DT) and rock density (RHOB) from Gulf of Mexico (GOM), North Sea (NS), Gardner et al. (1974), Birch (1961), Lindseth (1979) and Kozlovskaya et al. (2004) are given in Fig. 24. It is seen that the trend lines of GOM and NS fit Gardner's relation quite well. It can be deduced that Gardner's relation is suitable for the applications in hydrocarbon reservoir rocks. In contrast, other methods appear to fit lower rock densities at weaker rock section (i.e. greater DT), an indication of different applications, such as in the shallow soil in civil engineering, or in the subsurface aquifers in hydrogeology. All the relations tend to approach each other at stronger and heavier rock state (i.e. smaller DT and larger RHOB) while deviate from each other at weaker and lighter rock conditions.

\section{Histograms and probability of sonic travel time and density correlations}

For most formation and reservoir rocks, previous analysis indicates that the sonic travel time (DT) ranges primarily from 40 to $240 \mu \mathrm{s} / \mathrm{ft}$, while density (RHOB) ranges primarily from 1 to $3 \mathrm{~g} / \mathrm{cm}^{3}$. The statistical distributions of DT and RHOB may vary from well to well, which can be best represented by histograms. 


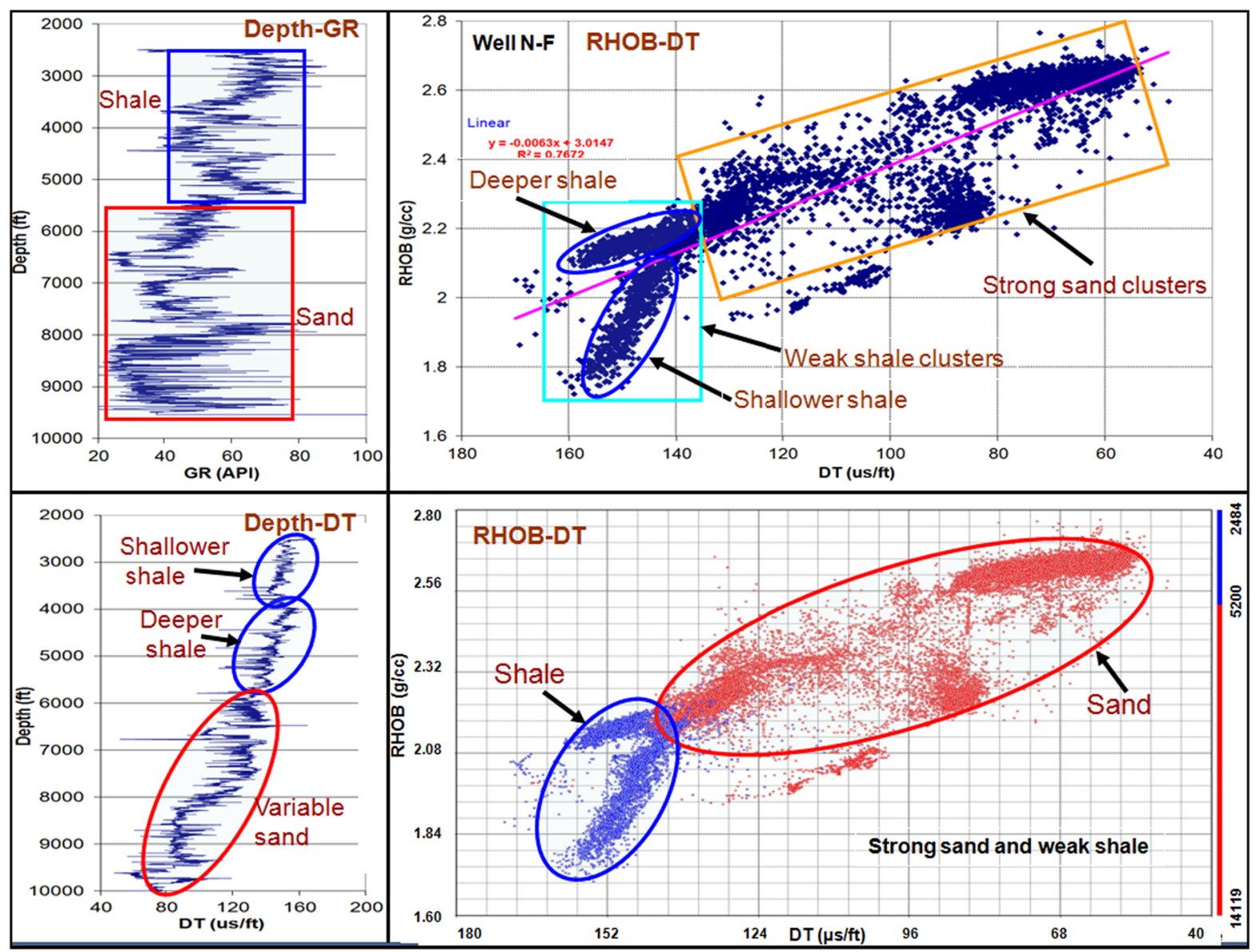

Fig. 12 Cross-plot of travel time (DT) and density (RHOB) for well N-F

A collection of histograms of DT and RHOB for all GOM wells are shown in Figs. 25 and 26. It is interesting to note that the DT and RHOB for most wells in GOM peak at about same range of DT and RHOB. In other words, it is deduced that the histogram distributions in most studied GOM wells are single peak in nature.

The representative histograms of DT and RHOB averaged from all wells in GOM are shown in Fig. 27. DT peaks at $126 \mu \mathrm{s} / \mathrm{ft}$. RHOB peaks at $2.24 \mathrm{~g} / \mathrm{cc}$.

The histograms of DT from 8 wells for NS (out of 11 wells) are shown in Fig. 28. It is apparent that most of histograms of DT for NS have two peaks at around DT values between 80 and $160 \mu \mathrm{s} / \mathrm{ft}$.
All the histograms of RHOB for NS are given in Fig. 29. The peaking of RHOB for NS appears to be more dispersed.

The representative histograms of DT and RHOB averaged from all wells in North Sea (NS) are depicted in Fig. 30. Twin peaks seem to be typical for both DT and RHOB data. DT peaks approximately between 80 and $160 \mu \mathrm{s} / \mathrm{ft}$. RHOB peaks between 2.22 and $2.64 \mathrm{~g} / \mathrm{cc}$.

Comparison of representative histograms of DT between GOM and NS is given in Fig. 31. The single peak of histogram for GOM is contrasted to the twin peaks of histograms for NS. It is seen that the primary 


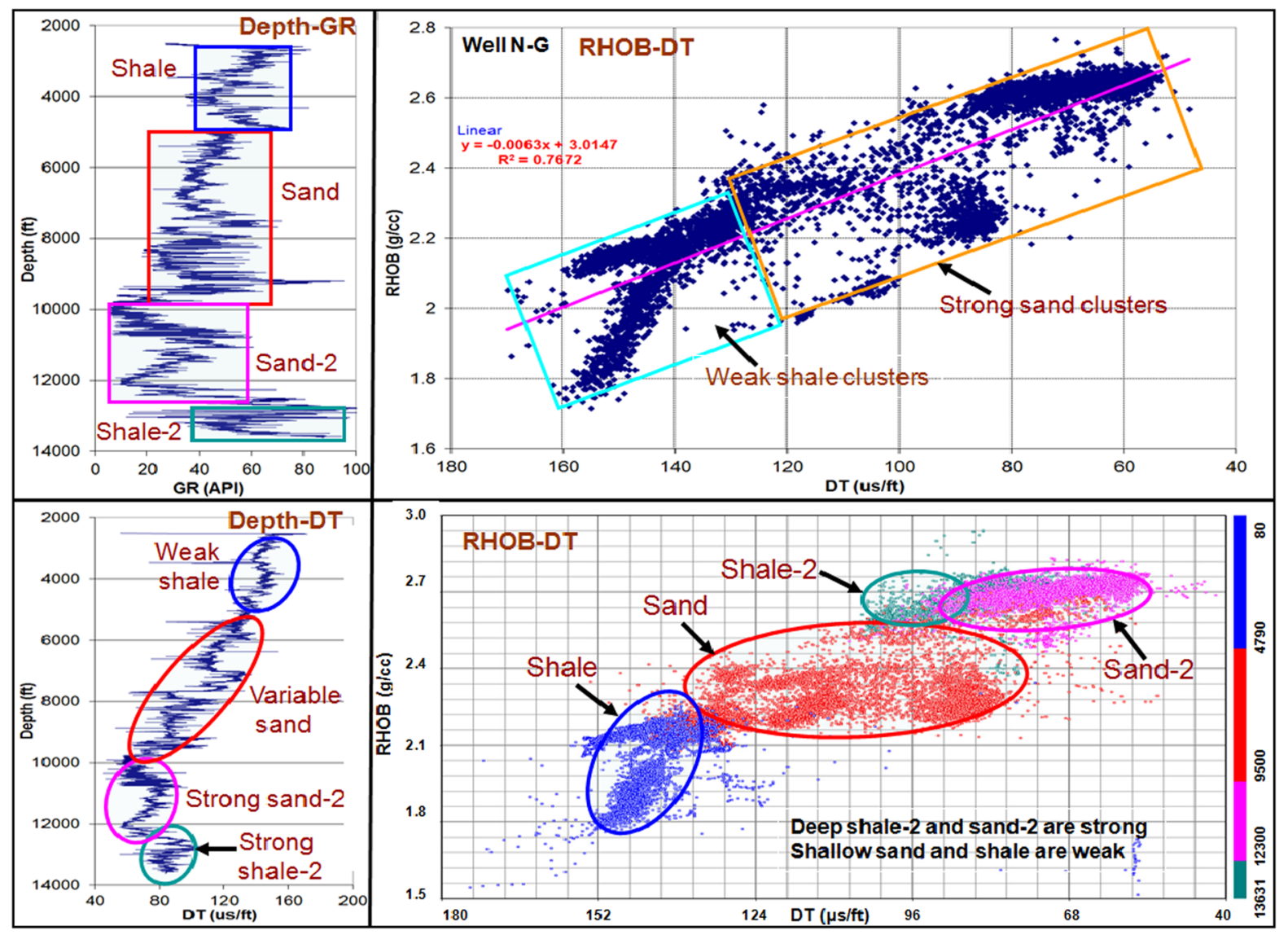

Fig. 13 Cross-plot of travel time (DT) and density (RHOB) for well N-G

range of DT for both GOM and NS is between 80 and $160 \mu \mathrm{s} / \mathrm{ft}$ with the average value DT at $120 \mu \mathrm{s} / \mathrm{ft}$.

Comparison of representative histograms of RHOB between GOM and NS is given in Fig. 32. It is interesting to note that even though the representative histogram of RHOB for NS has twin peaks as apposed to the single peak for GOM, the average values of RHOB at the peaks for both GOM and NS are almost same, i.e. $2.2 \mathrm{~g} / \mathrm{cc}$.

In summary, the dominant value of DT from GOM and NS is $120 \mu \mathrm{s} / \mathrm{ft}$, while the dominant value of RHOB from GOM and NS is $2.2 \mathrm{~g} / \mathrm{cc}$.

It is known that the linear relationship between sonic travel time DT and rock density RHOB shown in Eq. (7) differs from other DT-RHOB correlations given in the early section of this paper. This relation can be tested with uncertainty analysis in order to assess the risk involved using the correlation.

Monte Carlo simulation technique can be used to model the probability of different outcomes in a process that cannot easily be predicted due to the intervention of random variables (James 1980). Considering the transition from the frequency to probability as a random process due to the uncertainties of data generation, probability profiles can be derived from the frequency charts (Landau and Binder 2014).

Using the accumulative histograms of DT shown in Fig. 31 for GOM and NS, the probability of using the linear relationship in Eq. (7) to calculate RHOB can be illustrated in Fig. 33. This figure shows that the probability of using DT value around $120 \mu \mathrm{s} / \mathrm{ft}$ is about $50 \%$, which has been proved in the previous 


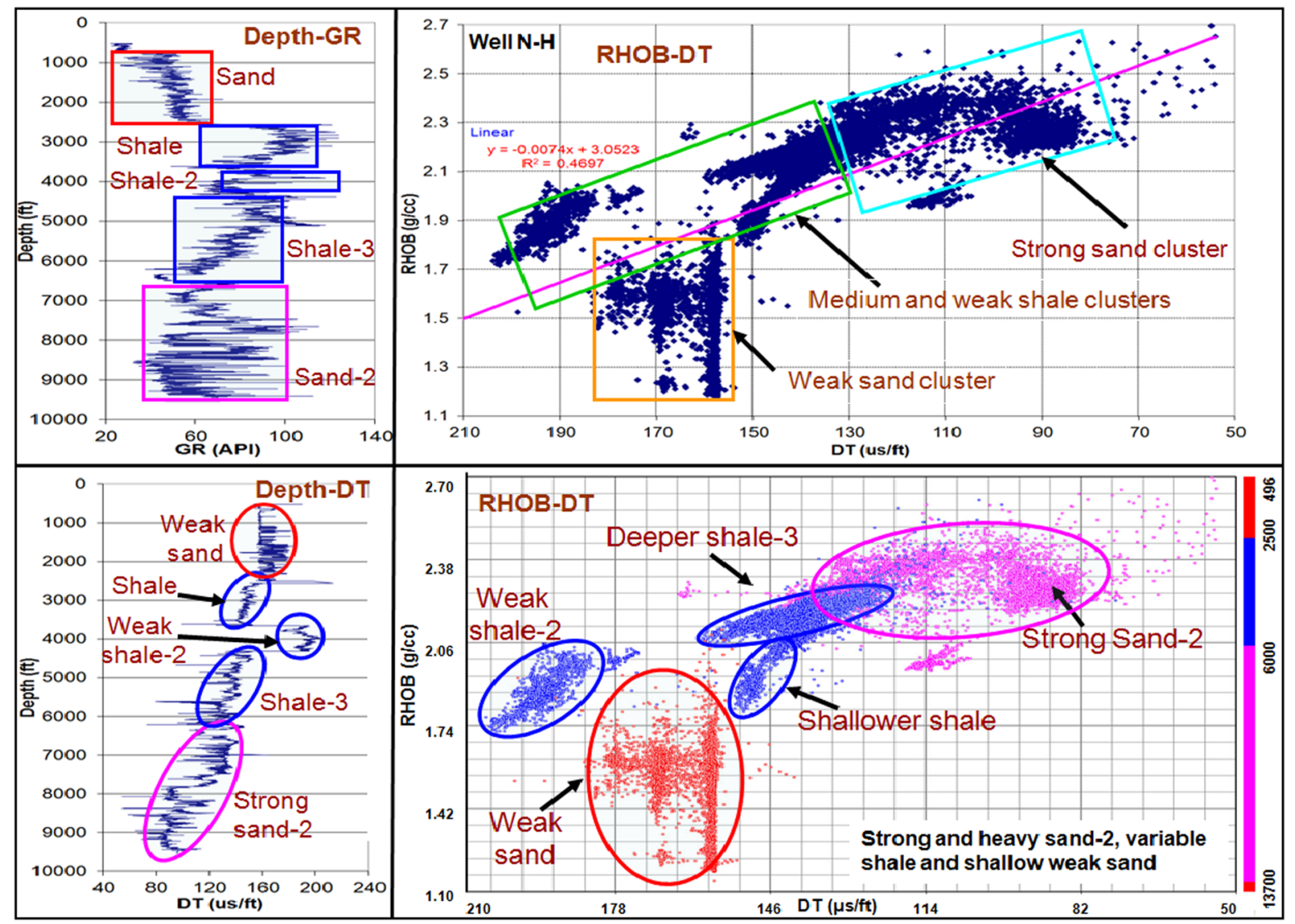

Fig. 14 Cross-plot of travel time (DT) and density (RHOB) for well N-H

deterministic calculation (i.e. the dominant value of DT for GOM and NS). The probability profile for GOM is uniform (more likely the histogram follows the normal distribution function). In contrast, the probability profile for NS is non-uniform, indicating variability of data from North Sea (NS). It can be observed that primary change of probability of using the linear relation to calculate RHOB is between 80 and $160 \mu \mathrm{s} / \mathrm{ft}$ in DT. Larger probability favors the larger DT, which is an indication that rock is weaker.

Equation (7) can be rewritten to calculate DT using the linear relation with RHOB:

$D T=\frac{\rho-A}{B}$
Using the accumulative histograms of RHOB shown in Fig. 32 for GOM and NS, the probability of using the linear relationship in Eq. (8) to calculate DT can be depicted in Fig. 34, which shows that the probability of using RHOB value around $2.2 \mathrm{~g} / \mathrm{cc}$ is about $50 \%$ that has been also proved in the previous deterministic calculation (i.e. the dominant value of RHOB for GOM and NS). It appears that the probability profile for GOM is uniform, which is in contrast to the non-uniform probability profile for NS. The primary range of drastic probability change for GOM and NS is between 1.5 and $2.5 \mathrm{~g} / \mathrm{cc}$. Higher probability range favors the greater value of RHOB, which indicates the heavier rock. 


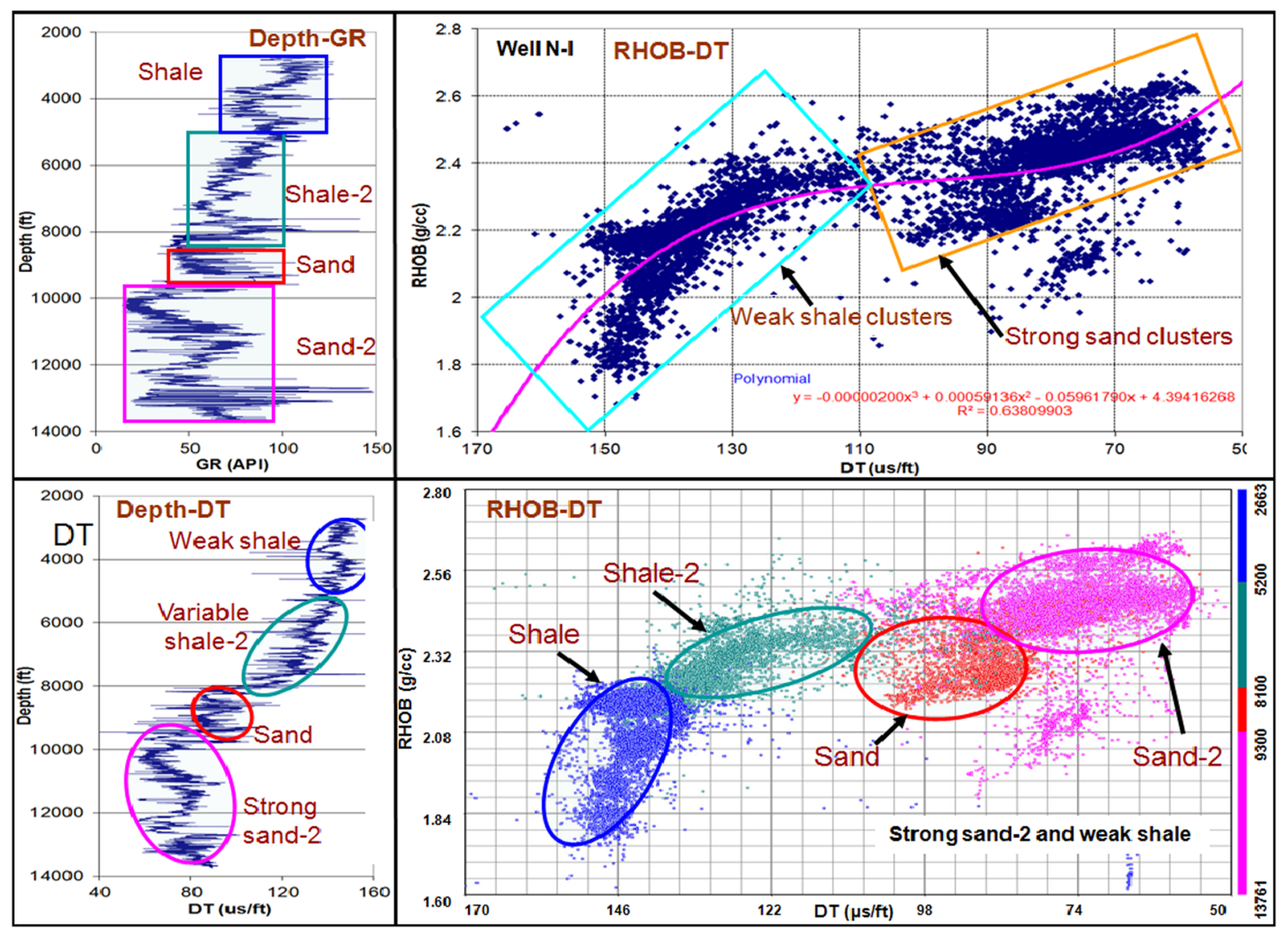

Fig. 15 Cross-plot of travel time (DT) and density (RHOB) for well N-I

\section{Conclusions}

The relations between sonic travel time (DT) and rock density (RHOB) can be useful to determine both values when only one value is available. The relation can act as a calibration method if both values of DT and RHOB are available but the quality of these data is in question.

Numerous relations between sonic velocity (i.e. an inverse of DT) and rock density had been developed in the past, noticeably the relationship by Gardner et al. (1974). However, these relations may be applicable to certain fields, or certain rocks, and may not be applicable when they are used in other fields, or in other rocks. This study uses the well data from Gulf of
Mexico (GOM) and North Sea (NS), primarily focusing on the formations featuring sand-shale sequences. The analysis starts with the intuitive approach to investigate the sonic velocity-density correlation due to lithological (i.e. from GR) and mechanical (i.e. from DT) impacts. The analysis is then extended to the deterministic analysis to define the correlations for GOM and NS fields. Further study includes the stochastic analysis on actual histograms of data from GOM and NS. Finally, the probability study is launched to assess the risk and uncertainty involving using the linear correlations between sonic travel time and density.

The following observations can be derived from these analyses: 


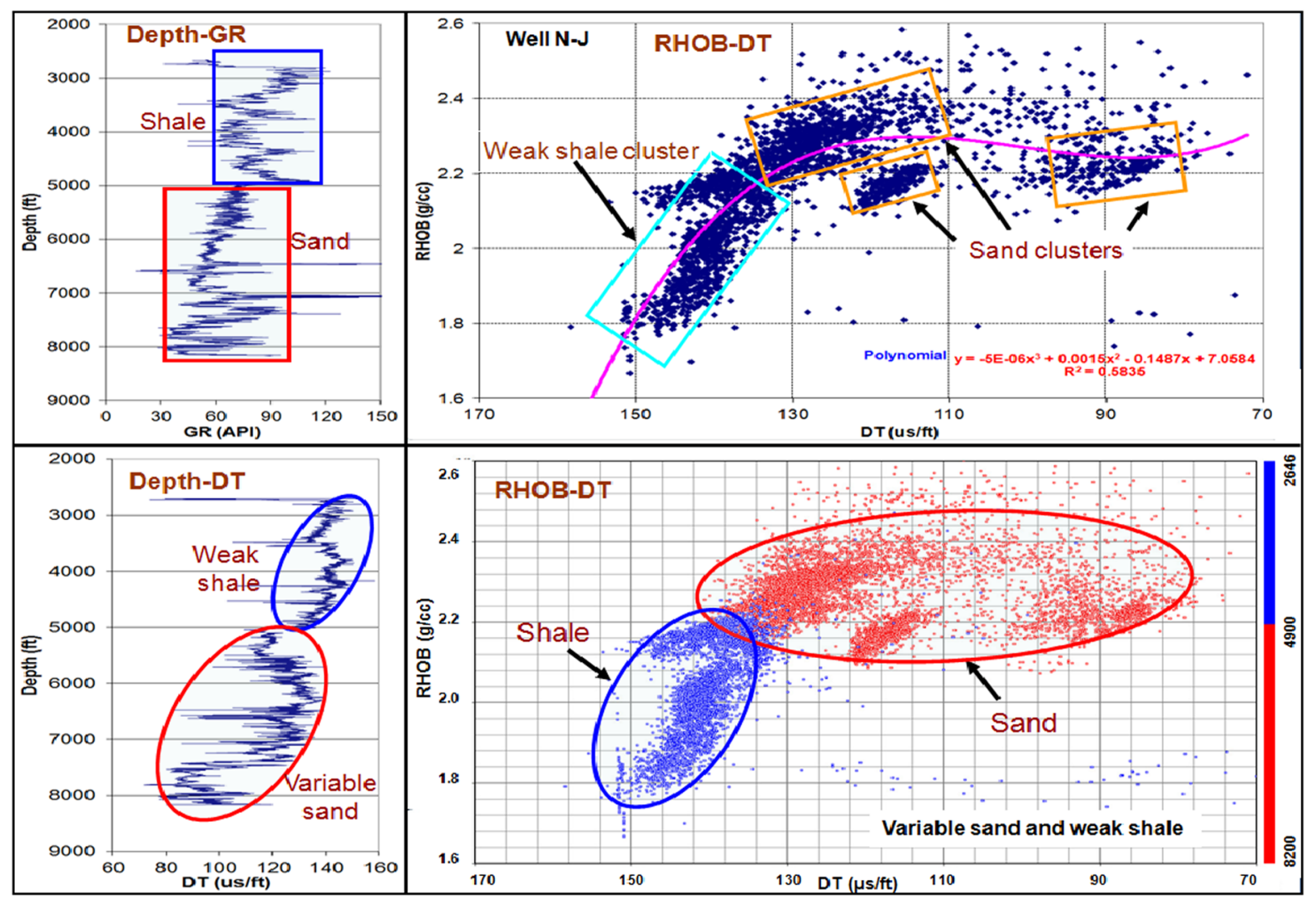

Fig. 16 Cross-plot of travel time (DT) and density (RHOB) for well N-J

- Lithological division is obvious for certain formations, which can be observed from several separate clusters of lithological identities.

- Non-linear tailing of data reveals the response of soft rock at shallow depth. It can result in the nonlinear sonic-density relation. However, the data from shallower depth are sometimes less valuable than the data from deeper depth since hydrocarbon lies mainly in the deeper formations. The linear sonic travel time-density relationship appears to be still viable if the non-linear section data are ignored.

- More uniform distributions of sonic travel timedensity cross plots as shown in most GOM data are the result of narrower range of GR (i.e. less fluctuating GR). In contrast, no-uniform clustertype distributions of sonic travel time-density cross plots as shown for most NS data represent wider range of GR (i.e. more fluctuating GR) in sand-shale sequences. In other words, the clusters are more distinct when the sand-shale separations are more obvious in GR.

- The dominant correlation between DT and RHOB from GOM and NS is linear. Even though the data from NS show more dispersion than the data from GOM, the linear trend lines between GOM and NS are similar in magnitudes and in slopes.

- Among all the correlations between DT and RHOB, the data from GOM and NS resemble the data from Gardner's correlation. Even though all 


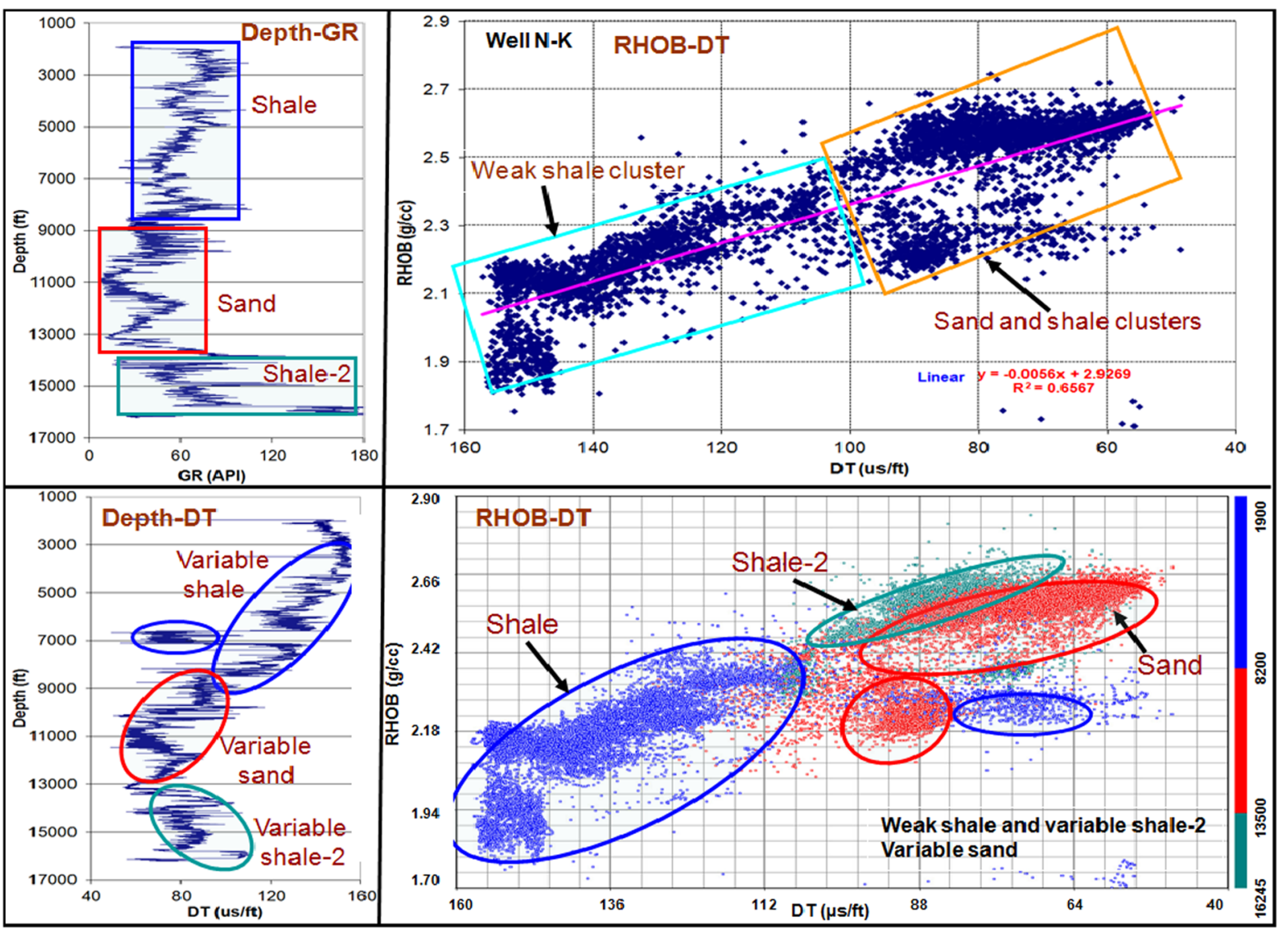

Fig. 17 Cross-plot of travel time (DT) and density (RHOB) for well N-K

the data show the consistent relations between DT and RHOB at denser and stronger rock ranges, the rest data fall into the low density intervals at weaker rock range, implicating the suitable applications to shallower and non-reservoir formations.

- With reference to the statistical data distributions of DT and RHOB, the distributions from GOM appear to be normal shape (i.e. single peak in histograms), while the distributions from NS seem to be abnormal in shape (e.g. two peaks in histograms). Further more, the peak of DT for GOM is around $120 \mu \mathrm{s} / \mathrm{ft}$, while the peaks of DT for NS are around 90 and $140 \mu \mathrm{s} / \mathrm{ft}$, respectively.

- The linear relation between DT and RHOB is tested using Monte Carlo type of simulations. The probability distributions are obtained from the accumulative histograms of DT and RHOB coupled with the linear correlations. The result shows 


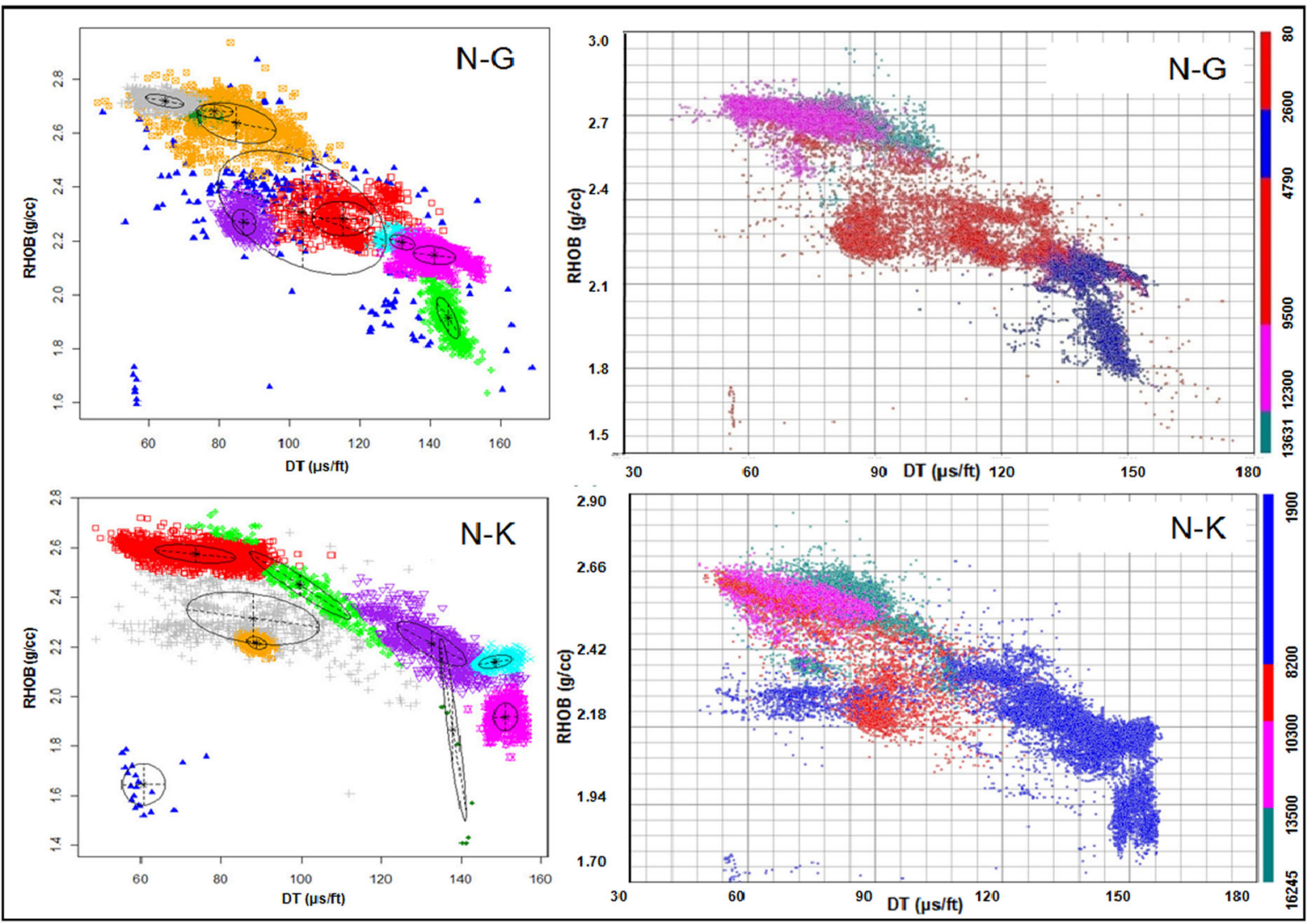

Fig. 18 Cluster-plots of travel time (DT) and density (RHOB) for wells N-G and N-K using R-program (left) and using present crossplots (right)

Fig. 19 Correlations between DT and RHOB for Gulf of Mexico wells

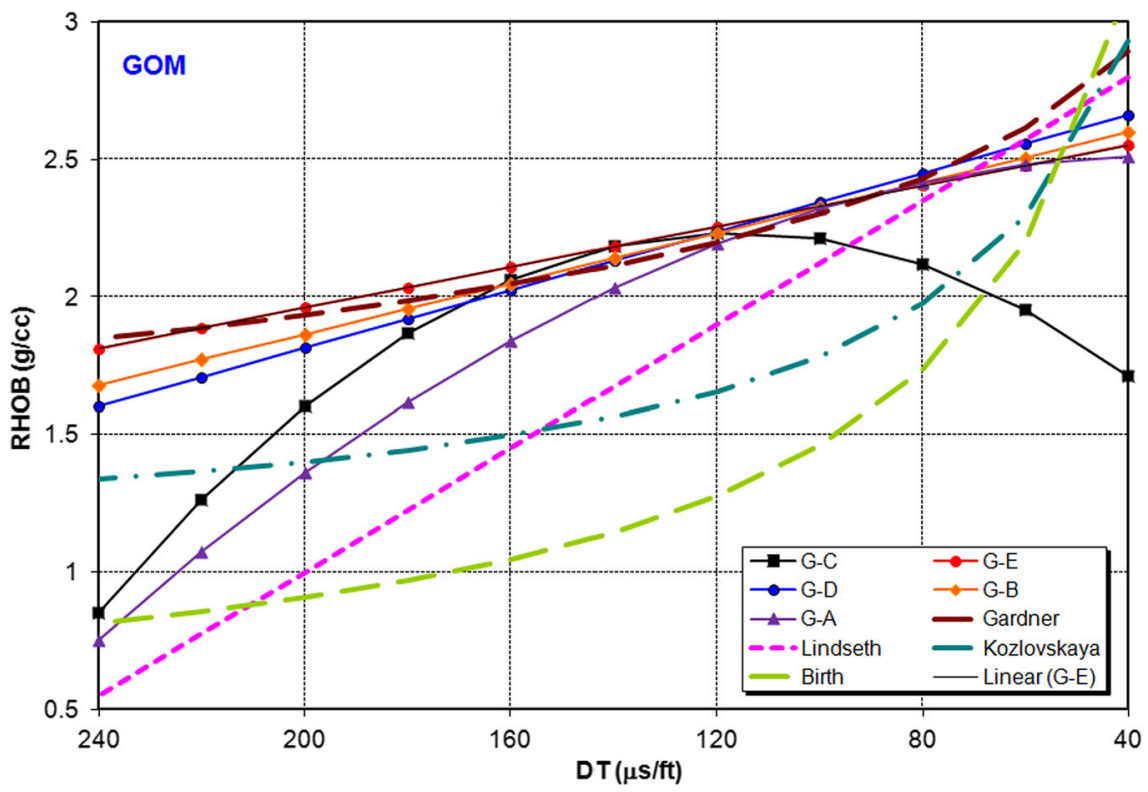


Fig. 20 Comparison between DT-RHOB for GOM (linear data) and Gardner method

Fig. 21 Correlations between DT and RHOB for North Sea wells
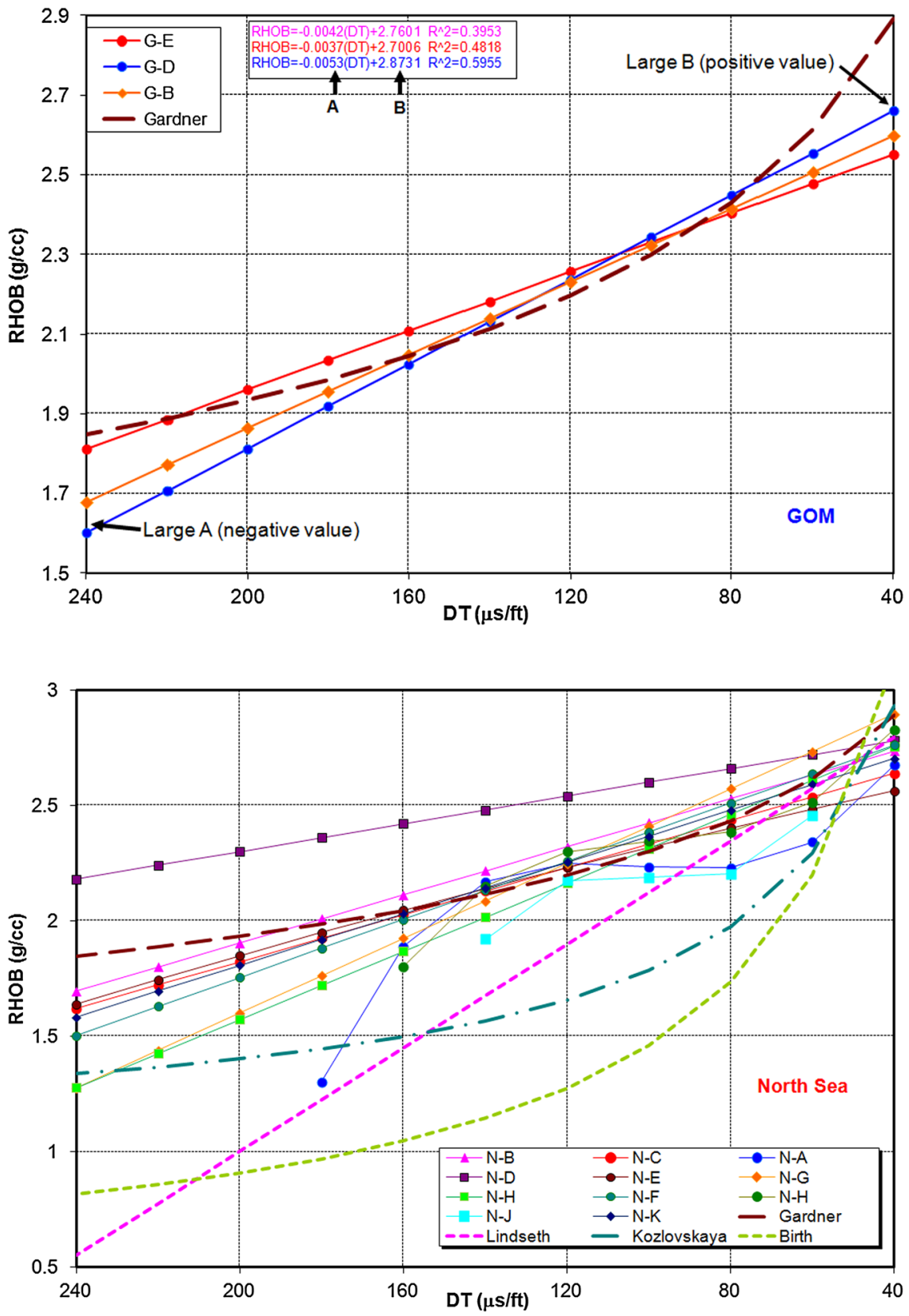
Fig. 22 Comparison between DT-RHOB for NS (linear data) and Gardner method

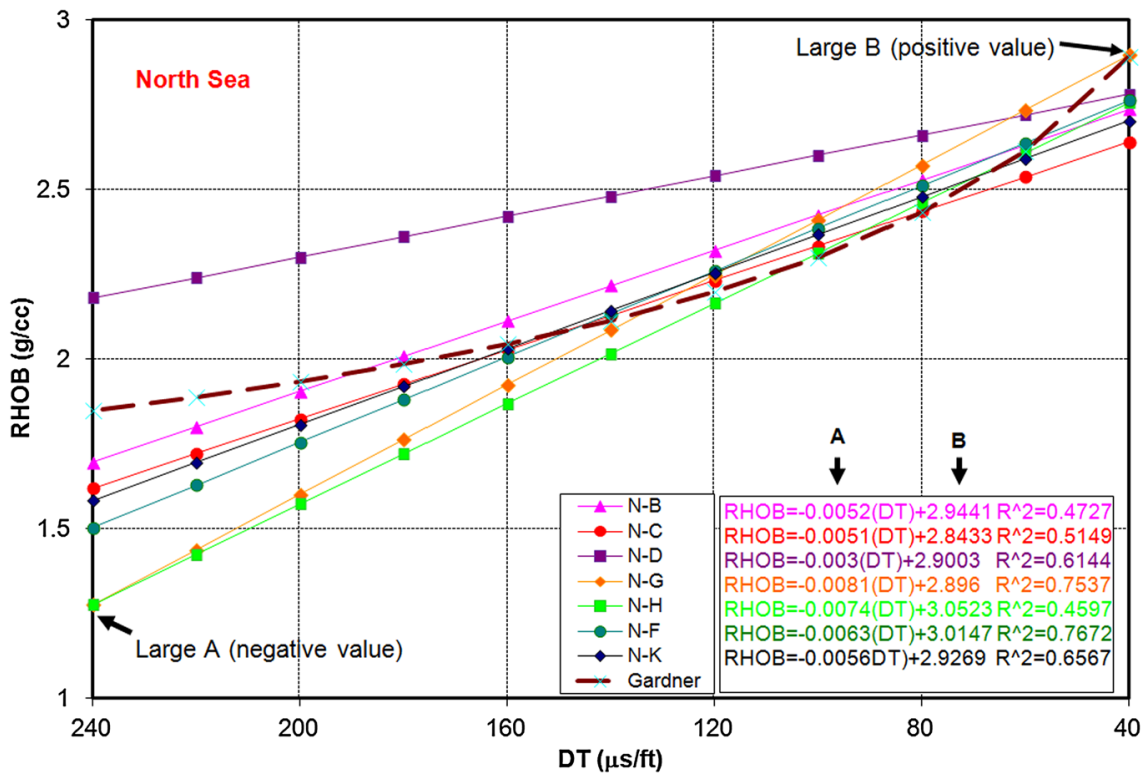

Table 1 Comparison of the ranges of coefficients "A" and "B" in Eq. (7) for the data of GOM and NS

\begin{tabular}{lll}
\hline Linear coefficient & A & B \\
\hline Gulf of Mexico & -0.0037 to -0.0059 & $2.6942-2.9593$ \\
North Sea & -0.003 to -0.0081 & $2.8433-3.22$ \\
\hline
\end{tabular}

the uniform probability distribution from GOM data and non-uniform probability distribution from NS.

- The investigation employs a comprehensive approach to determine the sonic velocity-density correlations, i.e.: (a) using physical intuitive approach to study the lithological and mechanical
Fig. 23 Comparison of trend lines of DT-RHOB correlations between GOM and NS

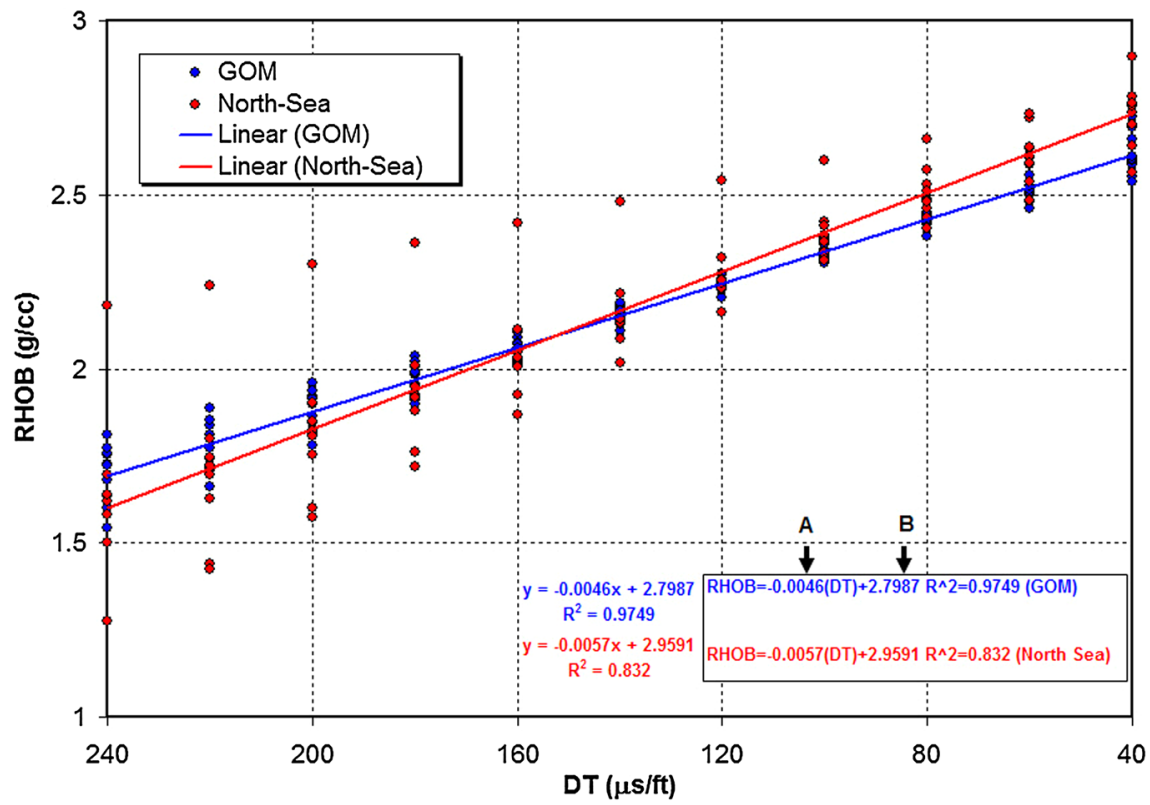


Table 2 Comparison of coefficients "A" and "B" in trend lines for GOM and for NS

\begin{tabular}{lll}
\hline Linear coefficient & A & B \\
\hline Gulf of Mexico (GOM) & -0.0046 & 2.7987 \\
North Sea (NS) & -0.0057 & 2.9591 \\
\hline
\end{tabular}

characteristics of the cross-plots; (b) using deterministic approach to define the correlations for GOM and NS fields; and (c) using stochastic approach to assess the risk and uncertainty involving using the linear correlations between sonic and density data.
Fig. 24 Comparison between travel time (DT) and rock density (RHOB)
Fig. 25 Histograms of DT for all GOM wells
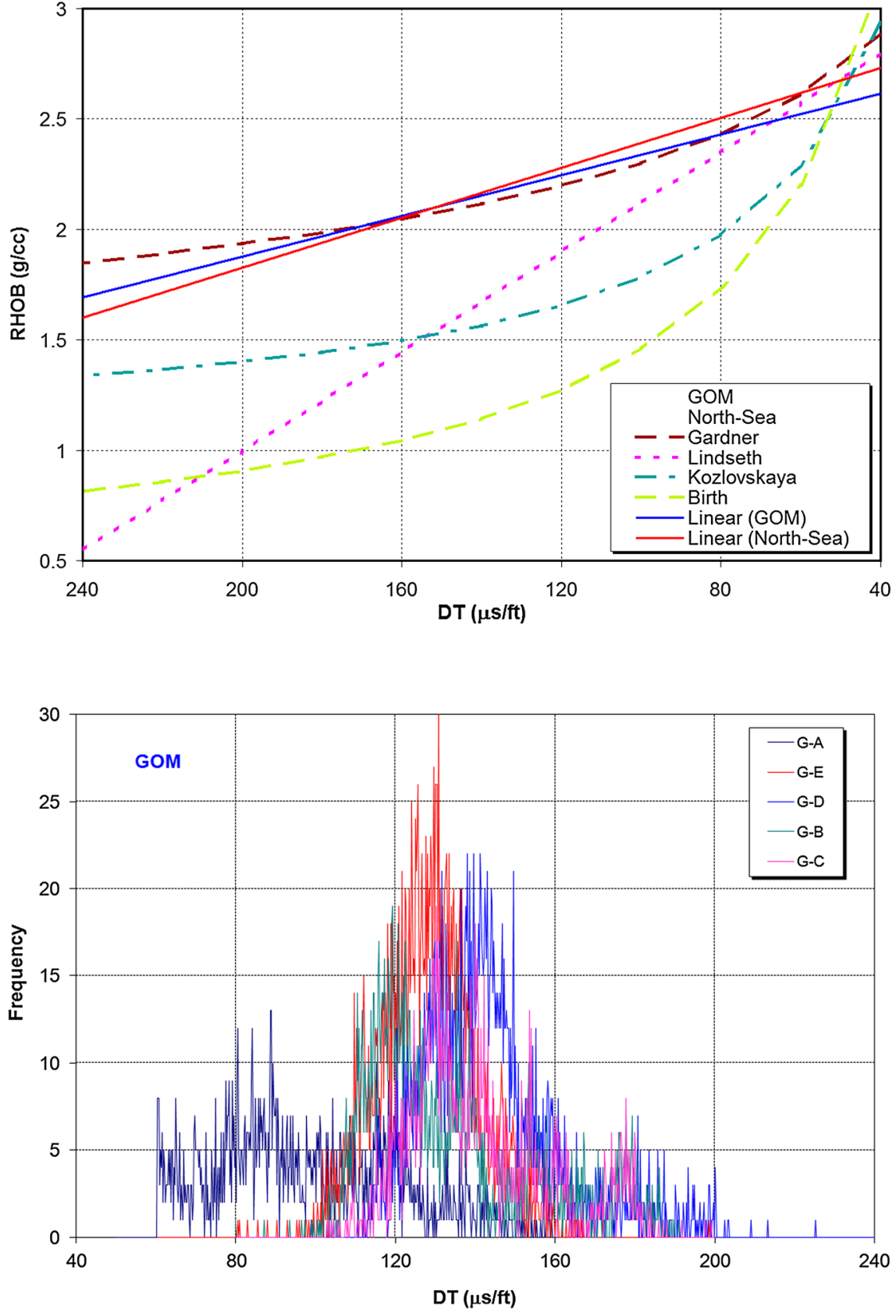
Fig. 26 Histograms of RHOB for all GOM wells

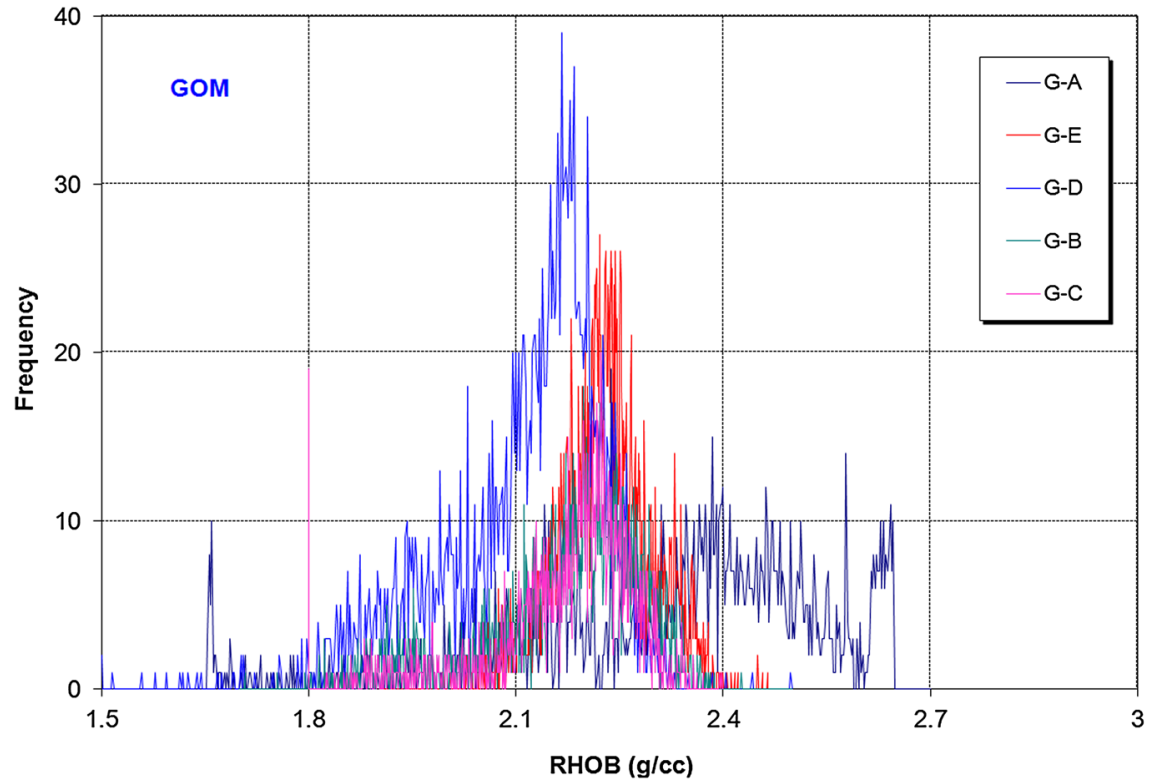

Fig. 27 Representative histograms of DT and RHOB for all GOM wells

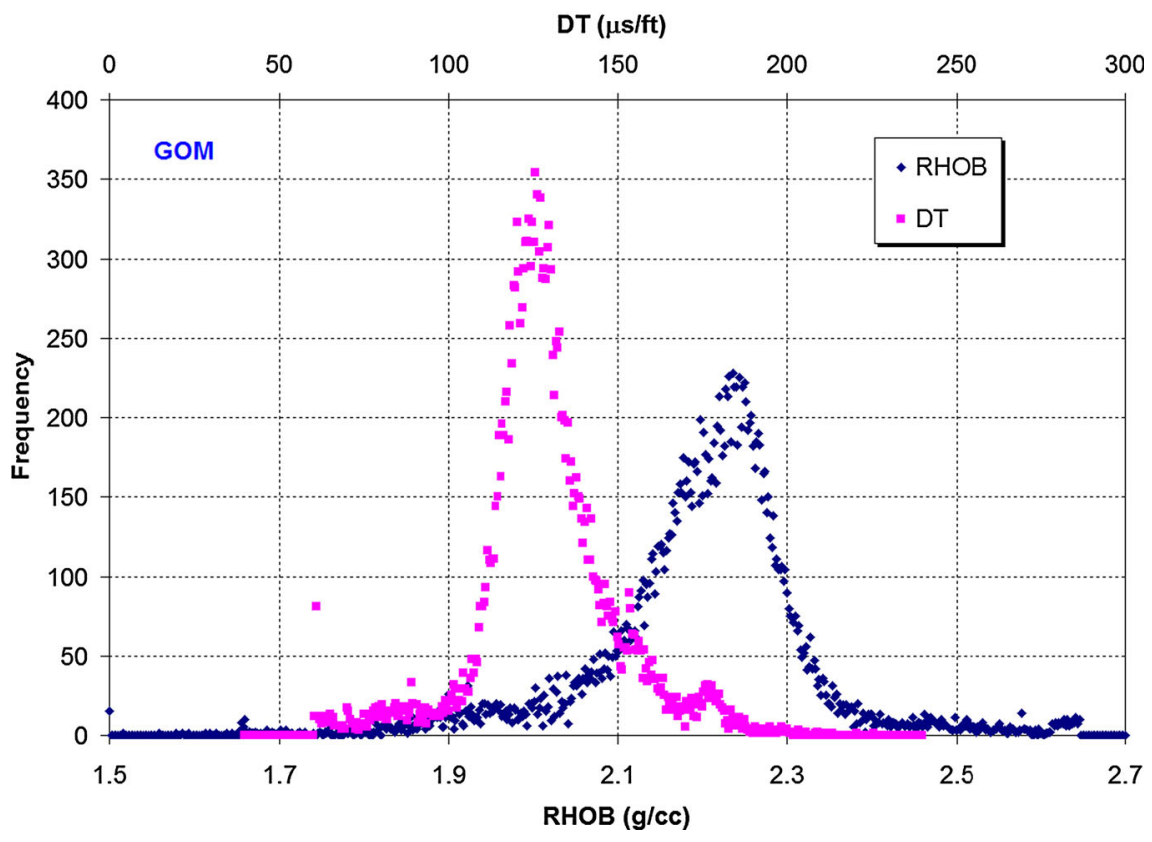


Fig. 28 Histograms of DT for eight NS wells

Fig. 29 Histograms of RHOB for all NS wells
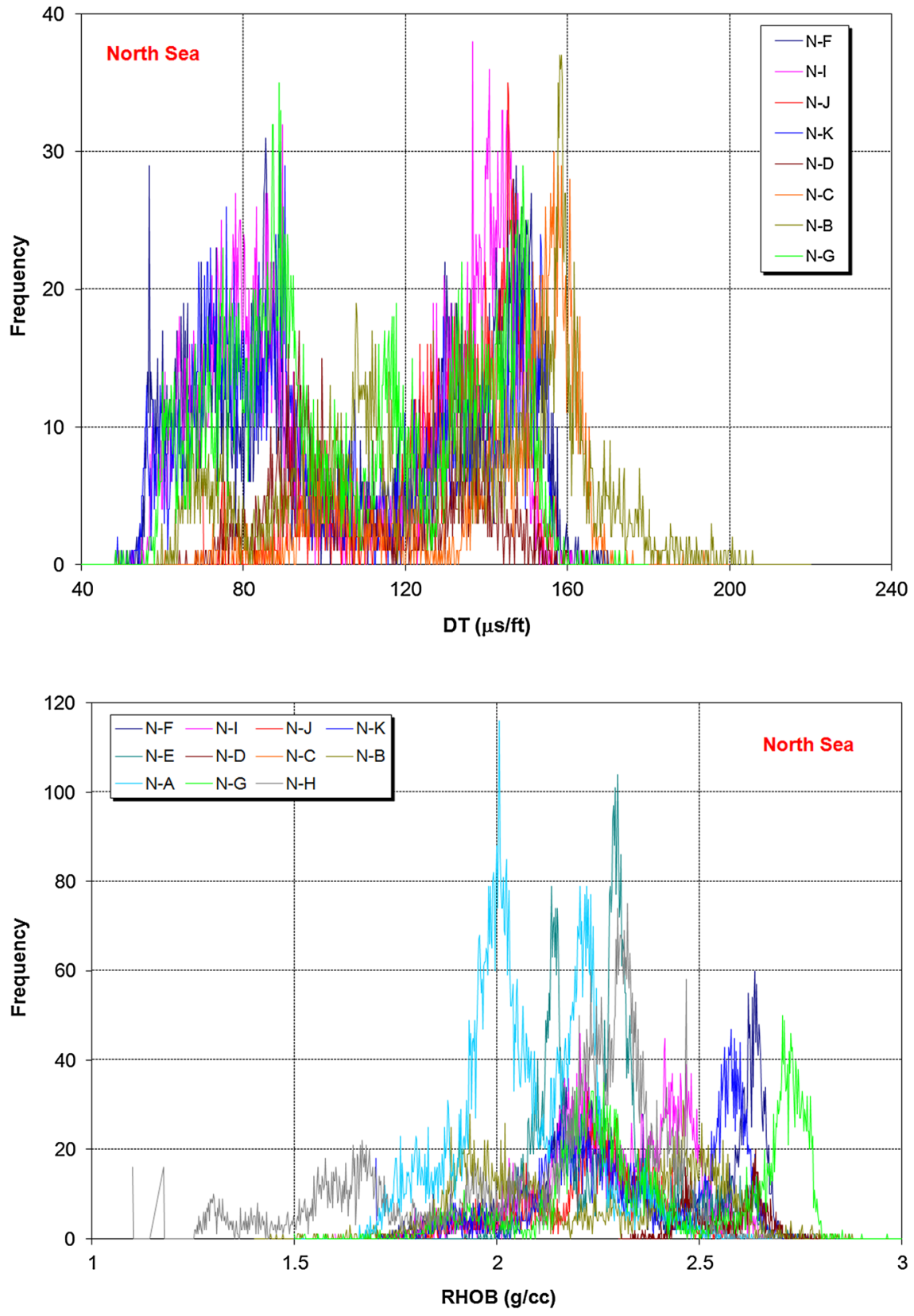
Fig. 30 Representative histograms of DT and RHOB for all NS wells

Fig. 31 Comparison of representative histograms of DT between GOM and NS
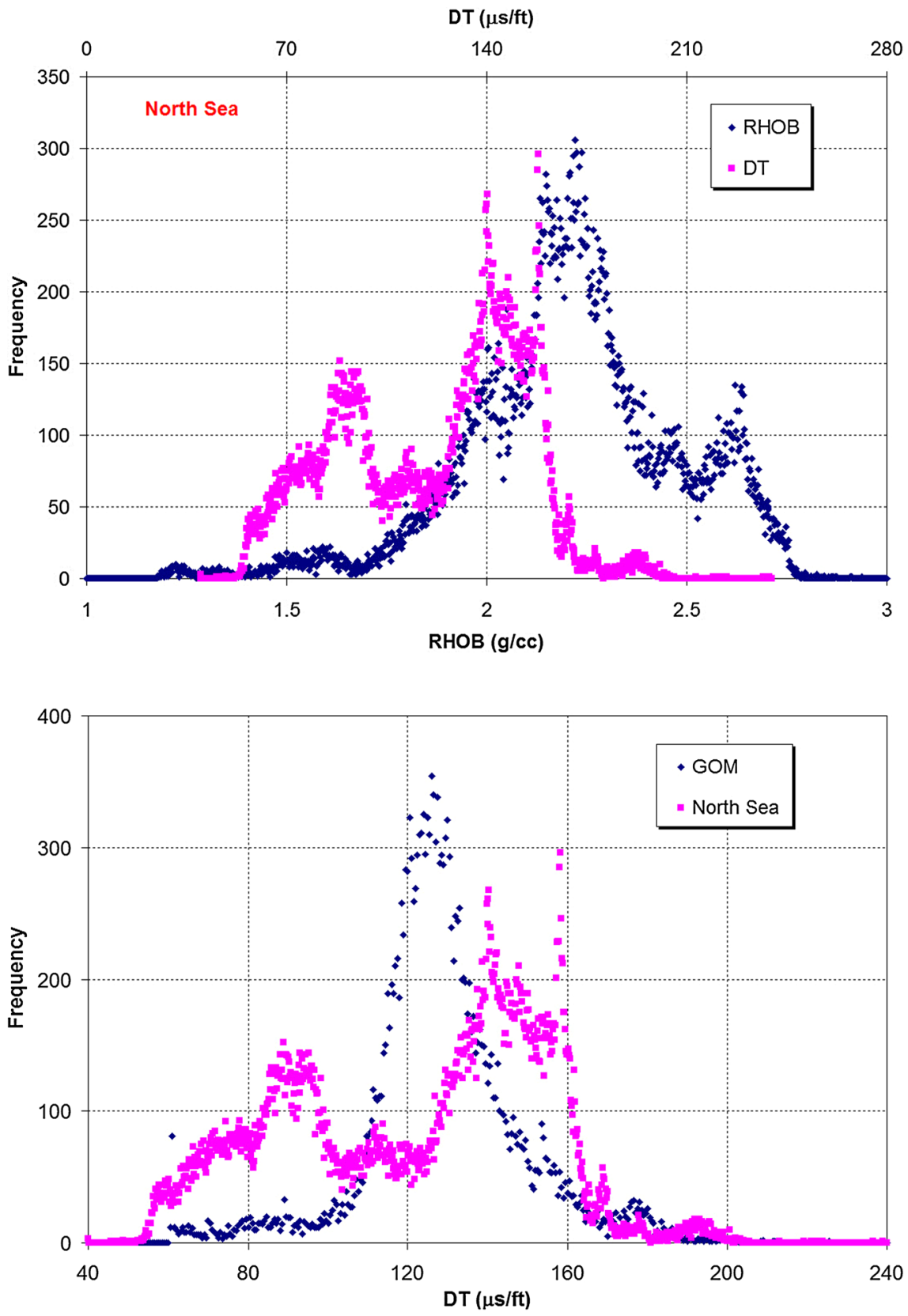
Fig. 32 Comparison of representative histograms of RHOB between GOM and NS

Fig. 33 Probability of using linear DT-RHOB relation to calculate $\mathrm{RHOB}$ from DT histograms for GOM and NS
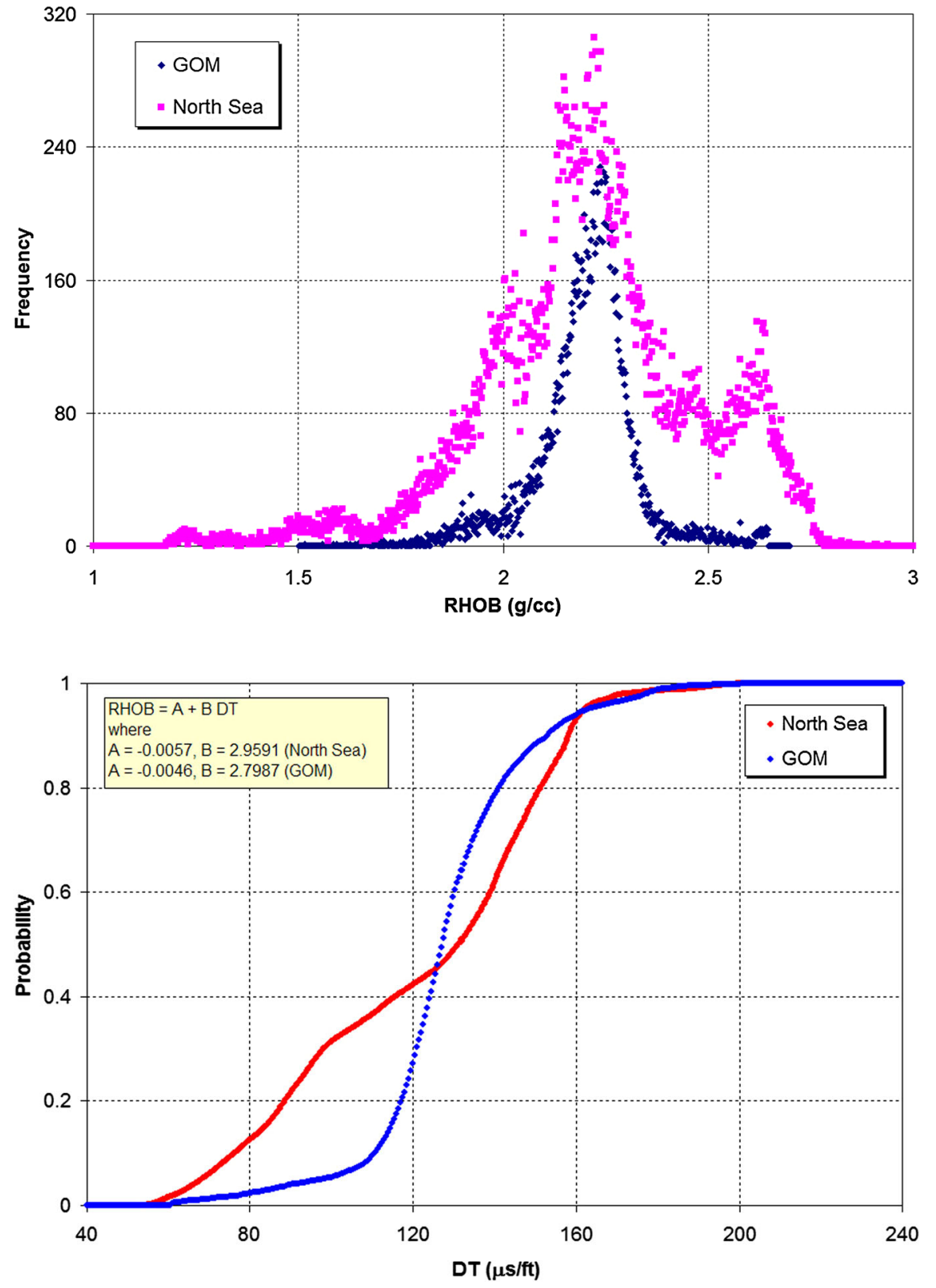
Fig. 34 Probability of using linear DT-RHOB relation to calculate DT from RHOB histograms for GOM and NS

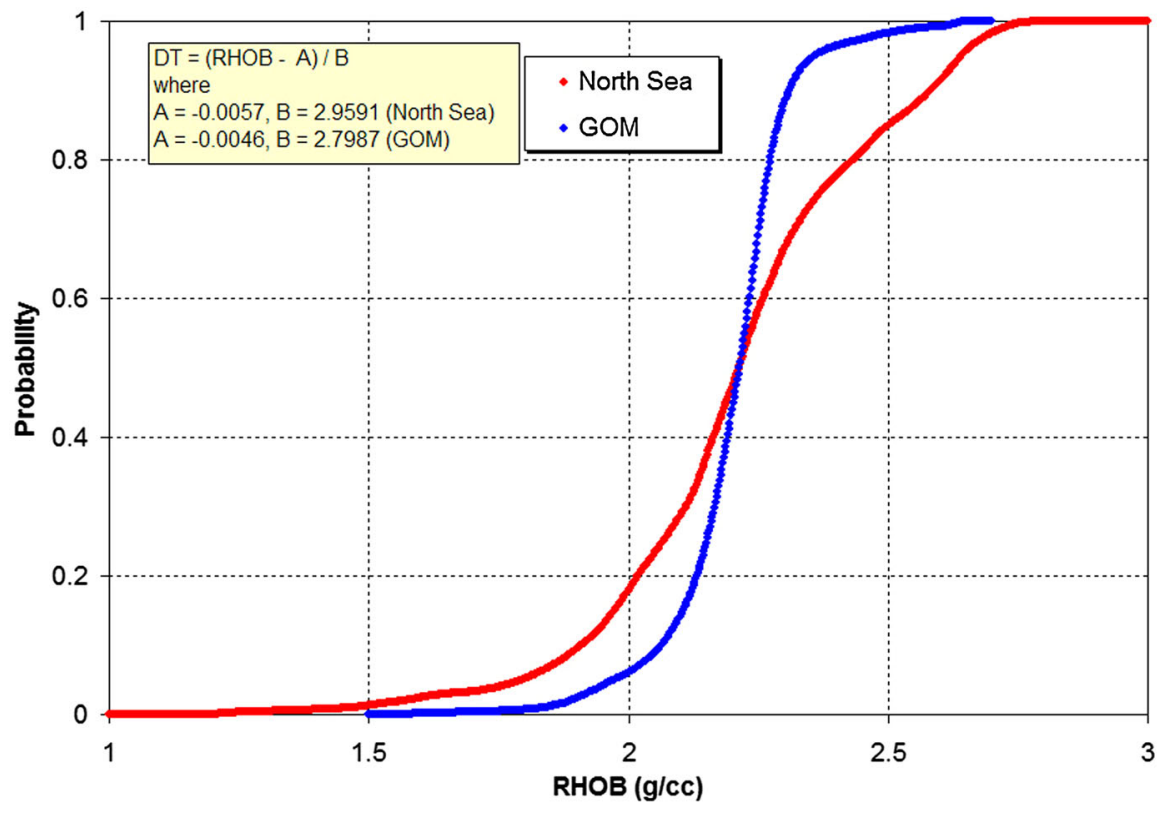

Acknowledgments The author would like to thank Dr. G. Li for his valuable contributions in completing this paper. Support of DEA project 161 is greatly appreciated.

\section{References}

Birch F (1961) The velocity of compressional waves in rocks to 10 kilobars (part II). J Geophys Res 66:2199-2224

Gardner GHF, Gardner LW, Gregory AR (1974) Formation velocity and density - the diagnostic basics for stratigraphic traps. Geographics 39(6):770-780

Horsfall OI, Omubo-Pepple VB, Tamunobereton-ari I (2013) Correlation analysis between sonic and density logs for porosity determination in the south-eastern part of the Niger Delta Basin of Nigeria. Asian J Sci Technol 4:1-005 Horsrud P (2001) Estimating mechanical properties of shale from empirical correlations. SPE Drill Complet 16(2):68-73

James F (1980) Monte Carlo theory and practice. Rep Prog Phys 43:1173-1189
Kozlovskaya E, Janik T, Yliniemi J, Karatayev G, Grad M (2004) Density-velocity relationship in the upper lithosphere obtained from P- and S-wav velocity models along the Eurobridge' 97 seismic profile and gravity data. ACTA Geophys Polonica 52(4):397-424

Lal M (1999) Shale stability: drilling fluid interaction and shale strength. In: SPE 54356, SPE Latin American and Caribbean Petroleum Conference, Caracas

Landau DP, Binder K (2014) A guide to Monte Carlo simulations in statistical physics, 4th edn. Cambridge University Press, Cambridge

Lindseth RO (1979) Synthetic sonic logs-a process for stratigraphic interpretation. Geophysics 44:3-26

Potter CC, Stewart RR (1998) Density predictions using $V_{p}$ and $\mathrm{V}_{\mathrm{s}}$ sonic logs, CREWES Research Report, vol 10

R Core Team (2012) R: a language and environment for statistical computing. R Foundation for Statistical Computing, Vienna. ISBN 3-900051-07-0

Sheriff RE, Geldart LP (1995) Exploration seismology, 2nd edn. Cambridge University Press, New York 